\title{
Liberalization, Technology Adoption, and Stock Returns: Evidence from Telecom*
}

\author{
Rabah Arezki, Vianney Dequiedt, Rachel Yuting Fan, \\ Carlo Maria Rossotto
}

Rabah Arezki, Chief Economist, African Development Bank, Senior Fellow, Harvard Kennedy School of Government, Research Fellow, Université Clermont Auvergne, CNRS, CERDI. Contact: arezki.econ@gmail.com

Vianney Dequiedt, Professor, Université Clermont Auvergne, CNRS, CERDI, Scientific Director, FERDI. Contact: vianney.dequiedt@uca.fir Rachel Yuting Fan, Economist, the Chief Economist Office of the Middle East and North Africa at the World Bank. Contact: yfan3@worldbank.org

C Carlo Maria Rossotto, Principal Investment Officer, Global Lead Upstream TMT, International Finance Corporation in World Bank Group. Contact: crossotto@worldbank.org

\section{Abstract}

The paper investigates the pace of technology adoption in telecom technology post liberalization and its effect on stock returns using a new global panel dataset. Results are twofold. First, evidence points to the complementarity between telecom liberalization and regulatory independence in driving a sustained pace of technology adoption. Second, results show a positive and economically significant effect of telecom adoption on stock returns pointing to significant spillovers of telecom to the rest of the economy.

Keywords: Liberalization, Technology adoption, Telecom, Regulation, Stock returns. JEL classification: F30, L11, 016.

* We thank Andrea Barone, Olivier Blanchard, Simeon Djankov, Hafez Ghanem, Daniel Lederman, Philippe Le Houerou, Tarek Masoud, Honore Ndoko, Paul Noumba and Lemma Senbet for excellent suggestions and comments. We thank Haytham Abushaban for research support. V. Dequiedt acknowledges support by the LABEX IDGM+ (ANR-10-LABX-14-01) within the program "Investissements d'Avenir" operated by the French National Research Agency (ANR). The findings, interpretations, and conclusions expressed in this paper do not necessarily reflect the views of the CERDI, the World Bank Group or the African Development Bank or the governments they represent. The CERDI, the World Bank Group and the African Development Bank do not guarantee the accuracy of data included in this work. 


\section{Introduction}

A global race over 5G is raging with important ramifications over domestic internet connectivity and global hegemony over technology. ${ }^{1}$ Economists have long studied cross-country differences in technology adoption and their consequences on economic growth (see Barro and Sala-i-Martin, 1997). To the extent of our knowledge, however, there is little systematic exploration of the telecom sector with a global perspective. Unlike with other general-purpose technologies, the standardized nature of telecom technology allows us to rigorously analyze the historical patterns of technology adoption over the five technology standards from $1 \mathrm{G}$ to $5 \mathrm{G}$. Interestingly, waves of telecom liberalization have led to different country outcomes in terms of the degree of sustained technology adoption and economic benefits. The present paper investigates the pace of technology adoption in telecom standards post liberalization and its effects on stock market returns using a new global panel dataset. This paper pays attention to country differences in institutional and policy frameworks and their interplay in explaining different outcomes.

To do so, we construct a novel indicator of the ranking in the adoption of telecom technology standards around the world. It allows us to document that very few countries have achieved a sustained pace of technology adoption in telecom following the liberalization of the sector. Figure 1 shows that the United States have experienced a sustained pace of adoption in telecom technology standards over time. The US have indeed consistently ranked at the very top over the past decades by adopting new standards as early as the latter were released. Interestingly, Latvia has been constantly improving in its ranking of technology adoption after a late start. In contrast, most other countries shown in Figure 1 have been "swinging" in terms of rankings. Indeed, most countries have been falling behind gradually after the liberalization waves in 1990s which have led to initial jumps in rankings - the initial jump capturing the relatively early adoption of a given telecom technology standard.

\footnotetext{
${ }^{1} 5 \mathrm{G}$ is the fifth generation technology standard for broadband cellular networks, which cellular phone companies began deploying worldwide in 2019, and is the planned successor to the $4 \mathrm{G}$ networks which provide connectivity to most current cellphones. See Supplementary Appendix for a detailed discussion.
} 
Figure 1. Evolution of Country Ranking in Adoption of Telecom Standards
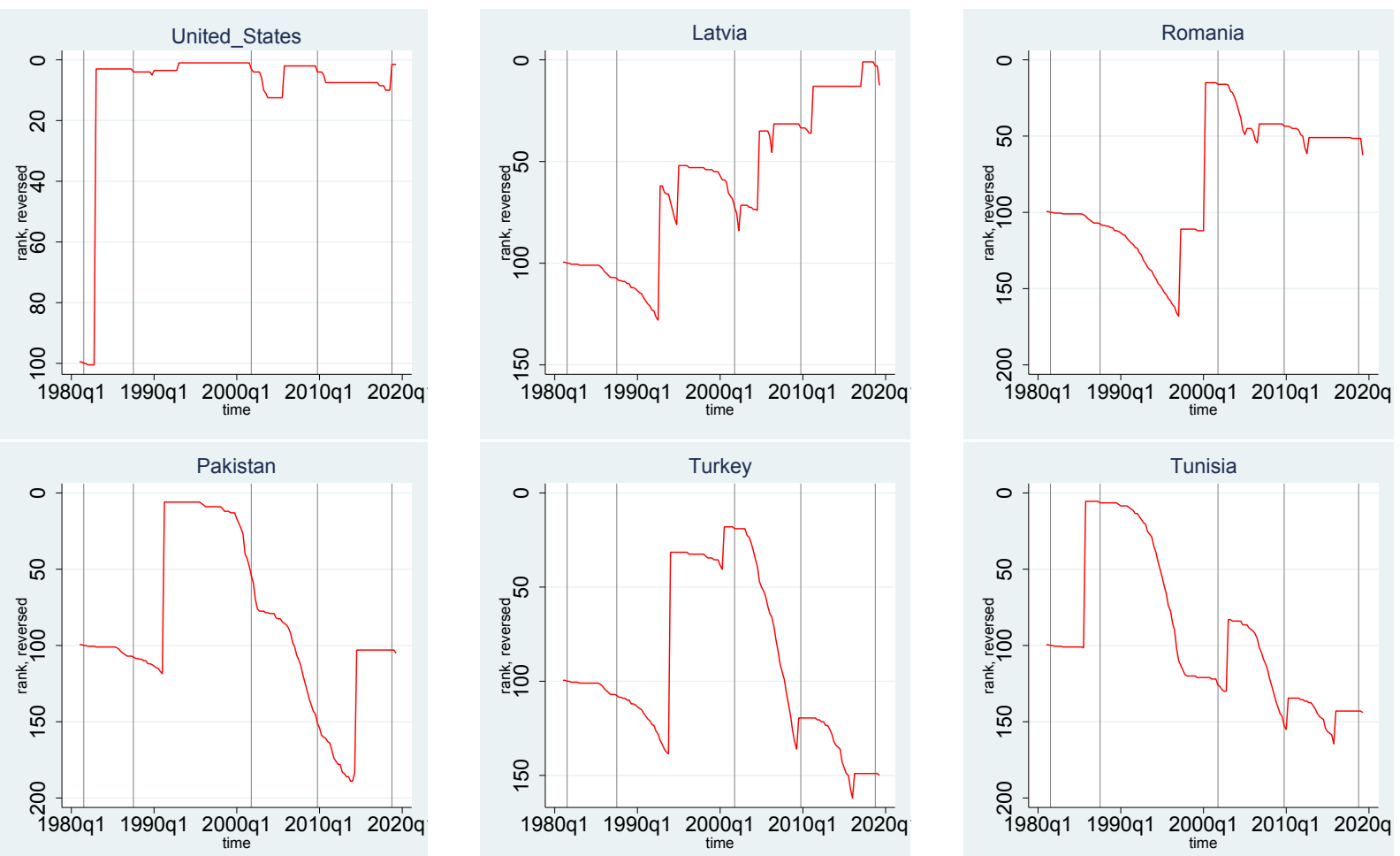

Sources: Authors' own calculation; Spectrum Launched Timeline, Telegeography.

Notes: The panels show the evolution of the indicator of the ranking of technology adoption. A higher value for the indicator for a given country indicates a higher ranking among all countries for a given year in telecom technology adoption. Time of the launch of $1 \mathrm{G}, 2 \mathrm{G}, 3 \mathrm{G}, 4 \mathrm{G}$, and $5 \mathrm{G}$ are marked as gray vertical lines for readers' reference. Details of the construction of this indicator are provided in Section II. Evolution of country rankings in adoption of telecom standards for all countries are provided in Appendix Figure 1.

Results from our more systematic empirical analysis are twofold. First, results show evidence of complementarity between liberalization and regulatory independence in driving a sustained pace of technology adoption. Second, results show positive and economically significant effects of telecom adoption on stock returns pointing to significant spillovers of telecom to the rest of the economy.

Our investigation on telecom industries across the world relates to several strands of literature. The first strand relates to the adoption and diffusion of new technologies. The (mobile) telecom technology possesses the three major characteristics of a general-purpose technology as detailed in Bresnahan and Trajtenberg (1996). The technology is pervasive since most sectors use mobile telecom technology to some extent. It gets improved over time, with five successive generations of the technology having been developed. It creates innovation spawning with many new services becoming possible, for instance geo-localized services.

Because they affect the whole economy, understanding the process of adoption and diffusion of generalpurpose technologies has been a cornerstone of studies focusing on cross-country differences in growth and total factor productivity patterns. Comin and Hobijn (2009a) have assembled the Cross-Country Historical Adoption Database (CHAT database) to document adoption of major technologies across the world over 
two centuries. Using this database in Comin and Hobijn (2010) they propose an indirect measure of countryspecific lags in technology adoption, based on the curvature of productivity.

Interestingly, our focus on the telecom sector allows us to have a direct and more precise measure of technology adoption lags since spectrum award and service launch timelines are documented in the Telegeography database. In Comin and Hobijn (2009b), the authors study the effect of institutional variables that affect the cost of lobbying and erecting barriers to entry on the speed of technology diffusion. They find that the effect is significantly larger when the technology has a close predecessor. They interpret this result as showing the importance of lobbying by incumbents in order to slow down technology diffusion. Our narrow focus on the successive generations of mobile technology allows us to scrutinize the countryspecific market structures in that industry and how it affects the incentives to adopt the latest technology. Cervellati et al. (2018) use the CHAT database to analyze the links between democratization, openness to trade and incentives for technology adoption. We share with the two latter references the idea that technology adoption is not only a decision taken by individual firms. In the mobile telecom sector, governments, whether benevolent or captured by specific interests, play a key role.

Accompanying the movement of telecom sector reforms across the world, the literature on the industrial organization of telecom has broadly focused on whether regulation would soon give way to competition policy after liberalization (see for instance Laffont et al., 1997). Stated differently, the literature asked whether a liberalized and mature telecom market provides sustained benefits to society without the need to regulate heavily. Therefore, this literature has taken a normative or positive approach to document the interplay between liberalization, privatization and regulation of the telecom industry. On the normative side, Cramton et al. (2011) or Rey and Salant (2018) have scrutinized spectrum allocation procedures that are common in liberalized mobile telecom markets, and how those procedures can be designed in order to guarantee downstream competition among the operators. On the positive side, cross-country analyses of telecom sector reforms have exploited the market and regulatory tracker data from the International Telecommunication Union (ITU). Privatization coupled with an independent regulation increases telecom performance. Privatization alone has few benefits. Few empirical studies focus on the mobile telecom sector. ${ }^{2}$ Taking stock of the experience accumulated in the early years of the mobile telecom industry, Gruber and Verboven (2001) analyzed the effects of different choices in terms of regulation of entry and technological standardization on the evolution of the industry. Faccio and Zingales (2017) establish the positive effect of following regulation best-practices, as measured by the ITU regulatory score, on various market efficiency measures. Then they turn to the question of why countries do not systematically follow regulation best-practices. They provide results supporting the regulatory capture theory. To the extent of our knowledge, our paper is the first to exploit the sequence of mobile telecom generations launches to document the dynamic performance of a regulated and very innovative industry.

The paper also relates more generally to a strand of the literature on macroeconomic effect of capital account liberalization and its consequences. Theory and empirical tests show that liberalization has significant effect on the cost of capital, investment, and economic growth. Most prominently, Henry (2000) and Bekaert et al. $(2000 ; 2005)$ provide evidence of reevaluation of stock prices using natural experiment of liberalization using a sample of emerging market economies. These papers however do not consider the role of the interaction between liberalization and competition and regulatory apparatuses. In this paper, we

${ }^{2}$ Wallsten (2001) focuses on Latin American and African Countries for the period 1984-1997. It establishes that competition is associated with lower prices and better access. Ahmed-Ezzat et al. (2018) study the sequencing of reforms in the case of the Middle East and North African countries. They highlight that creating an independent regulator before privatizing the incumbent is good for facilitating entry of competitors. 
use stock returns to evaluate the impact of liberalization of a specific sector-i.e. the telecom sectorcomplemented by regulatory independence.

The remainder of the paper is organized as follows. Section II presents the data used in our analysis. Section III shows the results from our empirical analysis. Section IV concludes.

\section{Data}

This section below describes the construction of a new indicator of country rankings of technology adoption in telecom. The section also presents other measures including telecom sector liberalization, foreign participation and quality of regulatory authority. Appendix Table 1 presents the list of variables used in our empirical analysis as well as sources. Appendix Table 2 presents basic descriptive statistics.

\section{Technology adoption ranking}

We construct an index of the pace of technology adoption by ranking each country on how quickly they adopt each telecom technology standard. This constructed dataset of ranking is a balanced data for 198 countries for forty years since 1980. We construct the indicator based on the ranking of the speed in technology adoption from $1 \mathrm{G}$ through $5 \mathrm{G}$. The source of data is based on Telegeography's Spectrum Launched Timeline, which lists the date at which each country has adopted a given technology standard.

Considering the balanced nature of the panel, the indicator precisely gives the ranking of any given country in the adoption of the telecom technology standard. Appendix Figure 1 shows the evolution of ranking for each country over the past decades.

In the following we illustrate how the indicator is constructed to capture the relative speed/delay in technology adoption. At each point in time, countries are grouped based on the latest standard they have adopted. Countries in group 1 include the ones which have adopted the most advanced standard. Countries in group 2 are the ones which have adopted the second newest standard available to date, and so on and so forth for the other groups. Within each group, countries are ranked in the order they have adopted a given standard. Consider $n$ countries at period $t$, if say $x$ countries have launched $4 \mathrm{G}$, while $y$ countries have launched 3G. Then in this period, the $x$ countries which have adopted 4G will rank from number 1 to $x$ with the country that first launched $4 \mathrm{G}$ being ranked first. The set of $y$ countries only using $3 \mathrm{G}$ will rank from $x+1$ to $x+y$, with the country that first adopted $3 \mathrm{G}$ ranking number $x+1$. If in the next period, say $t+1$, a new generation becoming available, say $5 \mathrm{G}$, this will move the frontier of technology. In period $t+1$, the country who first adopts $5 \mathrm{G}$ now ranks first, and all other countries' earlier rankings go down by one notch if they didn't adopt the standard. As more countries catch up and adopt 5G, countries not adopting new standards will fall further in the ranking pointing the delay in technology adoption. However, the indicator is such that after a given country adopts the latest technology standard, and before another new standard becomes available, that country's ranking won't be affected by other countries adopting the same technology afterwards.

Telecom technology standards come in waves going from $1 \mathrm{G}$ to $5 \mathrm{G}$. Figure 2 plots the number of countries which have adopted each technology standard. It starts in 1981, when 1G technology standard (the red area) was first adopted in Sweden. It took 14 years for the group of $1 \mathrm{G}$ adopter to reach 50 countries, while it took the group which has adopted $2 \mathrm{G}$ (the orange area) ten years to reach hundred countries. It took only six years for the group having adopted $4 \mathrm{G}$ (the gray area) to reach more than hundred countries. The standards that cover most countries and years (largest area in Figure 2) are $2 \mathrm{G}$ and $4 \mathrm{G}$. 
Figure 2. Global evolution of telecom technology adoption

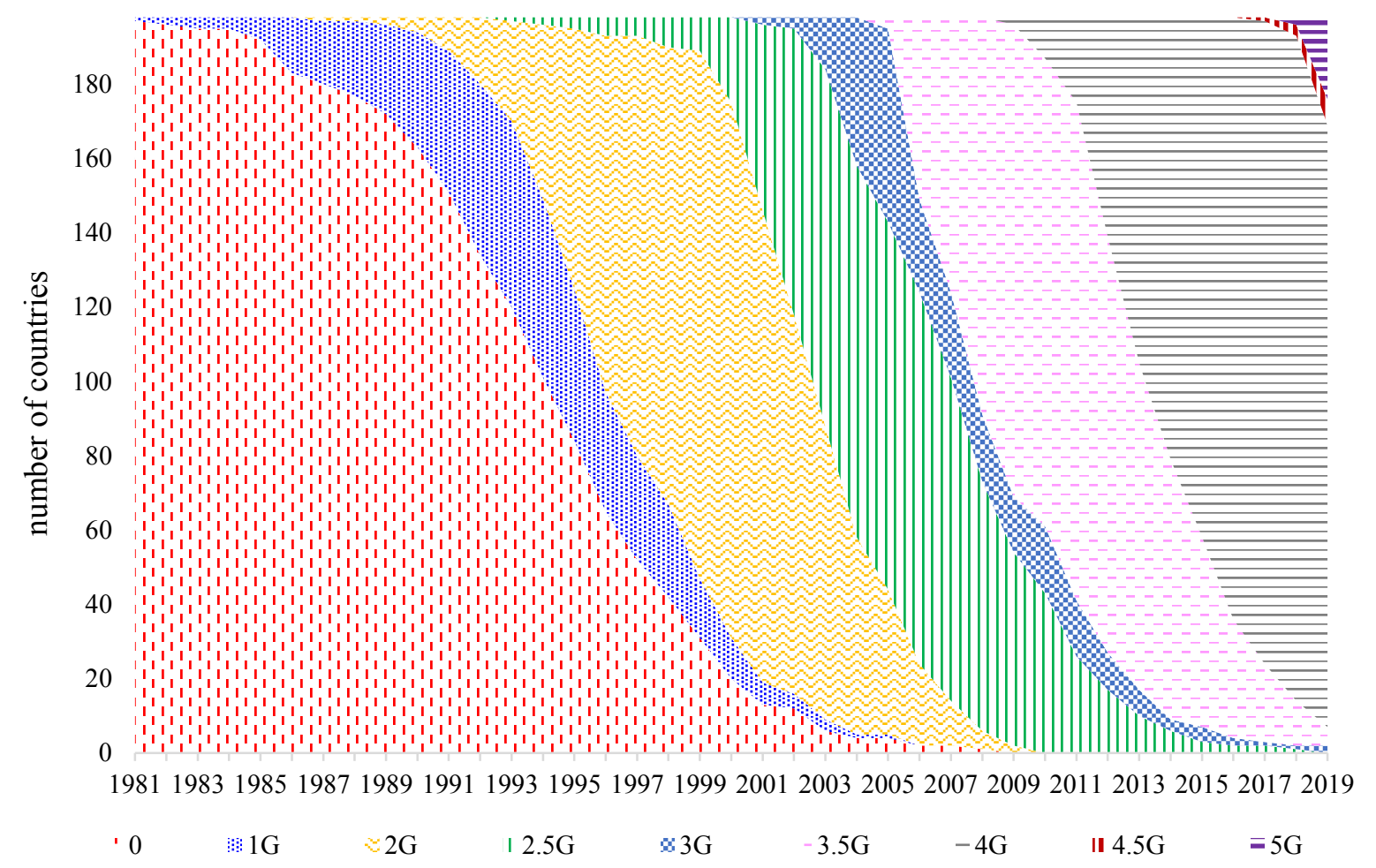

Source: Authors' own calculations; Spectrum Launched Timeline from Telegeography.

Notes: The indicator is constructed as the count of the number of countries that have adopted each technology standard over the years.

Now turning to the regional perspective on the evolution of telecom technology standards. ${ }^{3}$ Figure 3 shows the evolution of the ranking in adoption of technology standard based on simple averages of countries in each region. North America (NAC) namely US and Canada are leading in terms of the pace of technology adoption and have been steadily at the top of the ranking. Europe and Central Asia region (ECA) had risen in rankings until it steadily reached on average the $60^{\text {th }}$ place. Interestingly, both NAC and ECA have liberalized early and have independent regulatory apparatuses. The Middle East and North Africa region (MNA) have instead been swinging in the rankings. The region has fallen behind since 2008. Sub-Saharan Africa region (SSA) had been stagnant in terms of rankings. The ranking has improved since late 2000s.

\footnotetext{
${ }^{3}$ Regional classification is based on the World Bank.
} 
Figure 3. Regional evolution of technology adoption

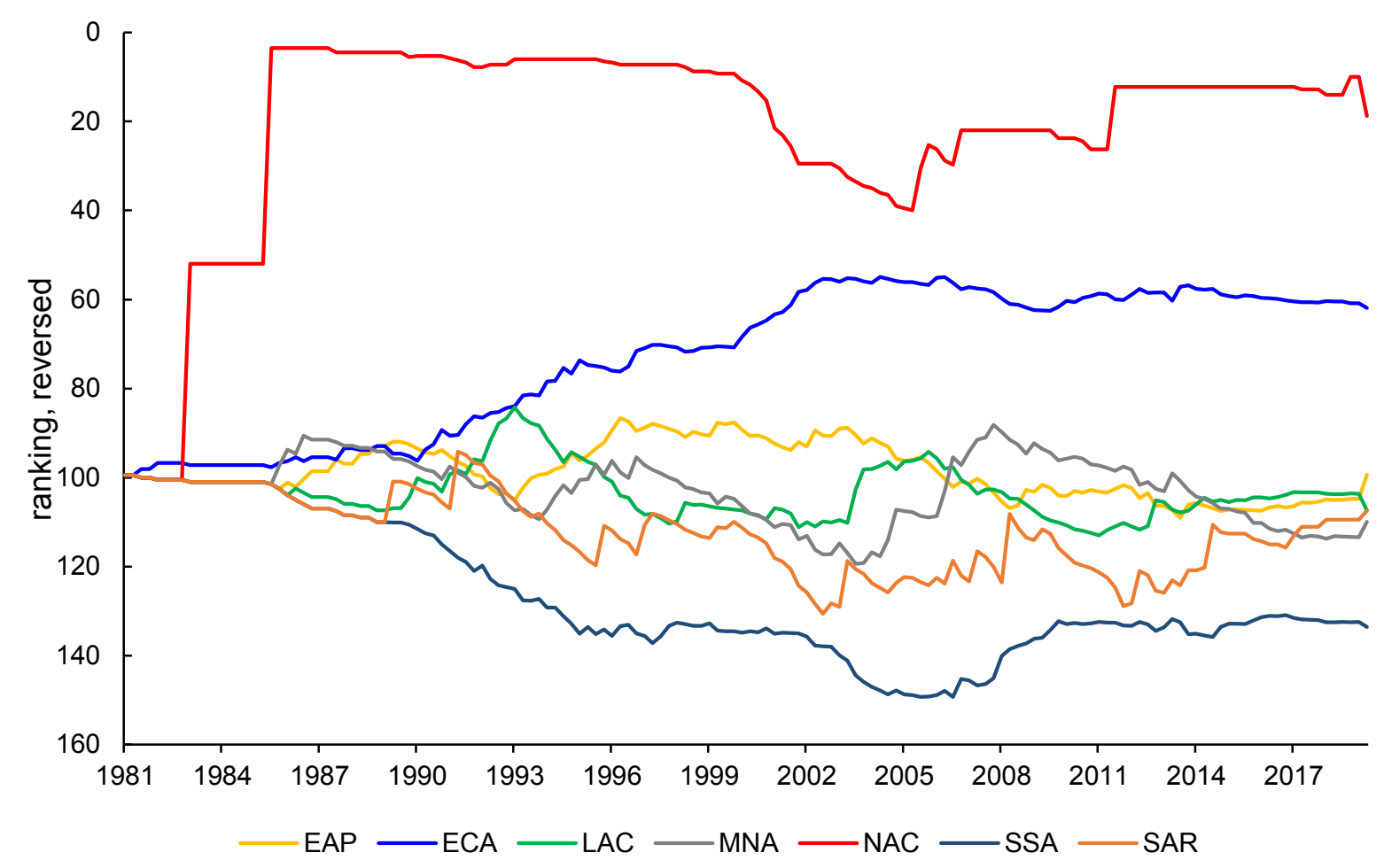

Sources: Authors' own calculations; Spectrum Launched Timeline from Telegeography.

Notes: The lines shows the evolution of the simple average of rankings from all member countries. EAP stands for East Asia and Pacific, ECA stands for Europe and Central Asia, LAC stands for Latin America and the Caribbean, MNA stands for Middle East and North Africa, NAC stands for North America, SAR stands for South Asia, and SSA stands for Sub-Saharan Africa.

\section{Liberalization and Foreign participation indicators}

In our empirical analysis, to measure liberalization of the telecom sector we use data on month and year for each country when telecom industry was liberalized. Data are from Telegeography, which is defined as the time when competition was instigated into the market. Liberalization is usually done via new legislation, allowing new players to offer services in competition with the incumbents. When countries have liberalized in stages, e.g. local telephony, domestic long distance, and international long distance, we use the date for international liberalization as the actual date for liberalization. The dataset is available for more than 200 economies and the earliest liberalization dates goes to as early as $1984 .{ }^{4}$

We also use an indicator of foreign participation to capture the effective liberalization of the telecom sector. We construct a new indicator that combines two datasets from GSMA Intelligence namely the market share

\footnotetext{
${ }^{4}$ United Kingdom, United States, Japan, and Isle of Man.
} 
database and groups-ownership database. The market share database provides market share of each telecom operator, and the groups-ownership database provides each operator's ownership. ${ }^{5}$

For each period, we define a group owner as being international, if the owner operates in multiple countries. To be more specific, for each owner, we list all countries for which that group owner has operations through its operators by more than 5 percent. ${ }^{6}$ If in a given period, there are more than one country listed in the group owner' operations, then the owner is considered "international" in that period. Then, foreign participation rate for country $c$ at time $t$ is calculated as follows:

$$
f_{c, t}=\sum_{p \in P_{c, t}}\left(s_{p, c, t} \times \sum_{w \in W_{p, t}} n_{w, p, c, t}\right),
$$

where $P_{c, t}$ is all operators that have positive market share in country $c$ at time $t$, and $W_{p, t}$ are all international owners of operator $p$ at time $t$. Market share of operator $p$ in country $c$ at time $t$ is denoted by $s_{p, c, t}$, and its ownership to owner $w$ is denoted by $n_{w, p, c, t}$.

For example, assume that a given country has two operators, $\mathrm{A}$ and $\mathrm{B}$, each with a market share of $s_{A}$ and $s_{B}$, respectively. Domestic owner $D_{A}$ owns $d_{A}$ percent of operator A, international owner $I_{A 1}$ owns $i_{A 1}$ percent, and international owner $I_{A 2}$ owns $i_{A 2}$ percent. Domestic owner $D_{B 1}$ owns $d_{B 1}$ percent of operator $\mathrm{B}$, domestic owner $D_{B 2}$ owns $d_{B 2}$ percent, and international owner $I_{B}$ owns $i_{B}$ percent. Then the foreign participation rate in this country is equal to $s_{A} \times\left(i_{A 1}+i_{A 2}\right)+s_{B} \times i_{B}$.

Waves of liberalization in the telecom sector especially in the 1990s for the developing world have led to significant levels of foreign participation. Figure 4 shows that Latin America and the Middle East and Africa have reached amongst the highest level of foreign participation. Regions where domestic telecom operators are dominant in their local markets but yet have a global reach because of their competitiveness have reached lower level of foreign participation. This the case of North America, Western Europe, East Asia and Australia. Other countries which have lowest foreign participation are countries which have limited effective liberalization because of state owned enterprise dominating their local markets. These state-owned enterprises however do not have a global reach as they are not competitive. Figure 5 shows the evolution over time. There is a clear upward trend in foreign participation in the telecom sector, even so we are using data which are only available from 2000 onwards. Latin America and the Caribbean as well as Europe and Central Asia and the Middle East and Africa have had the fastest increases.

${ }^{5}$ When ownership data are not available, we researched operators' ownership structure including whether the owner is domestic vs. international. We use trustworthy sources including Telegeography, the stock exchange commission, Internet Society, and interviews of telecom experts.

${ }^{6}$ We only consider owners beyond the 5 percent threshold to capture significant voting rights. 
Figure 4. Foreign participation in telecom sectors around the world

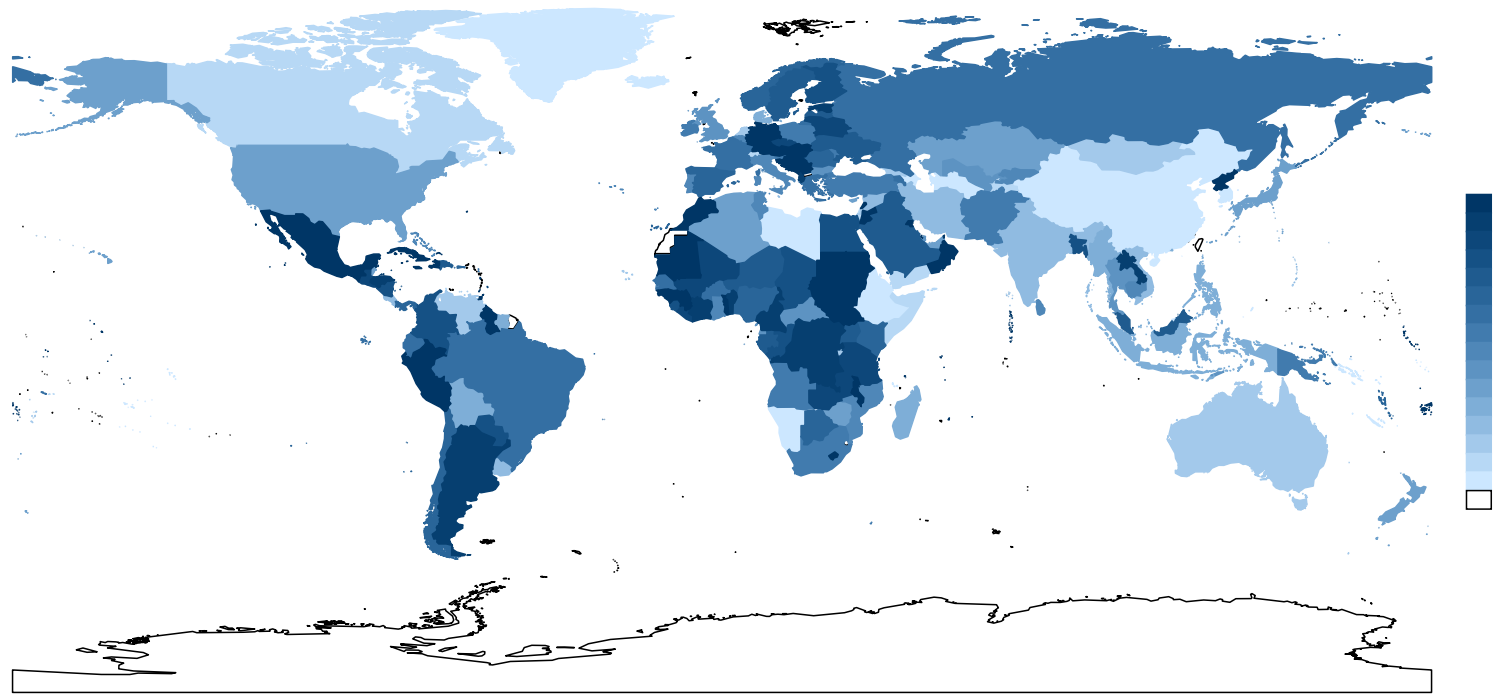

Sources: Authors' own calculations; GSMA Intelligence.

Notes: Foreign participation rate is shown as a percentage of market share as of 2018.

Figure 5. Regional evolution of foreign participation in the telecom sector

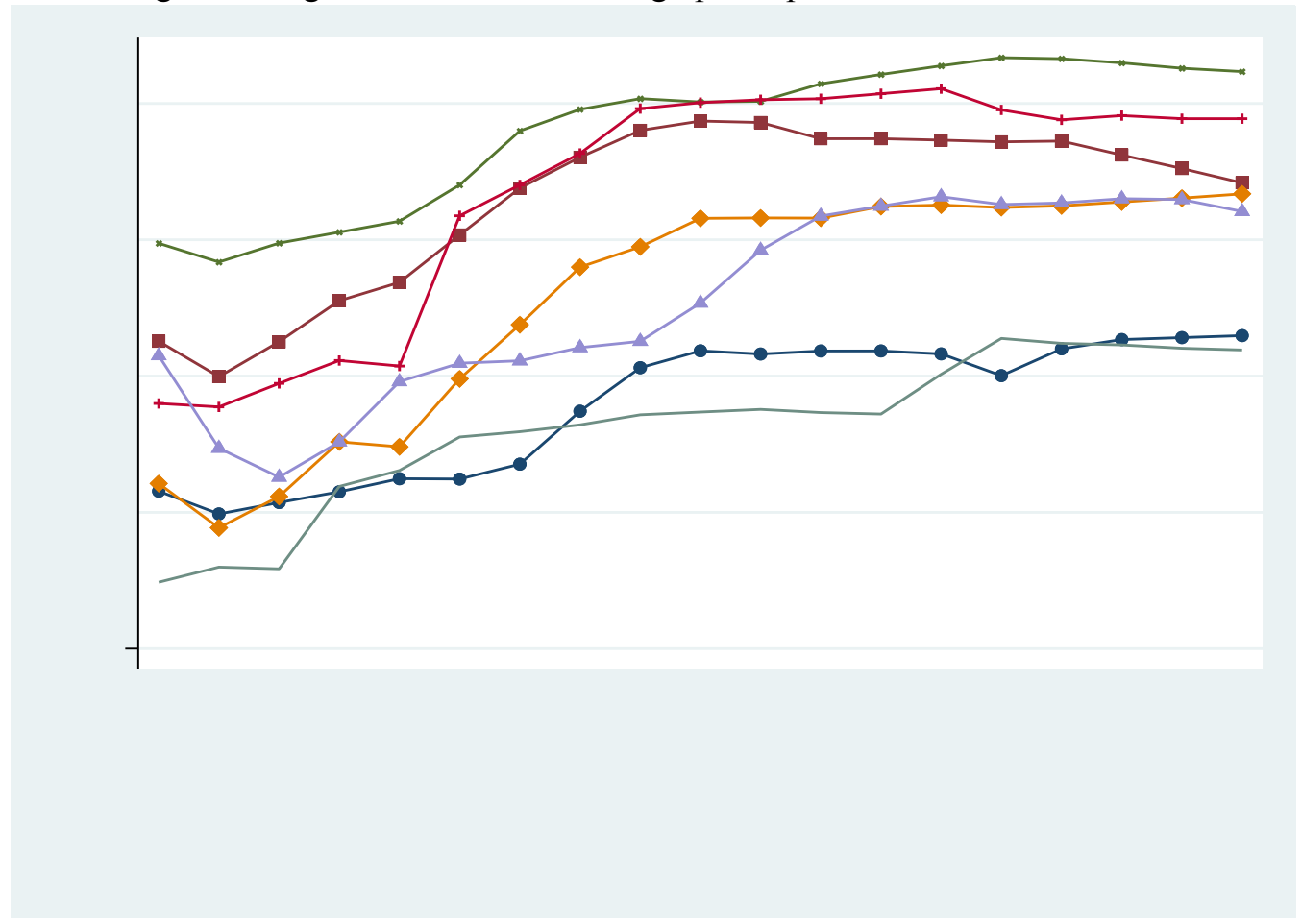

Sources: Authors' own calculations; GSMA Intelligence.

Notes: Foreign participation rate is shown as a percentage of market share. The lines show simple average of foreign participation rate in its member countries. 


\section{Regulatory independence}

To capture the independence of the telecom regulatory authority, we use data from the International Telecommunication Union regulatory trackers. The data covers 180 countries from 2003 to 2017. We focused specifically on cluster 1 that gathers information on the regulatory authority. The score of this cluster is based on the sum of the score of the answers to ten related questions. Each answer has a full score of 2, such as separate telecom/ICT regulator, autonomy in decision making, accountability, etc... A higher score indicates a more independent regulatory authority. We have this indicator normalized between zero and one when we use it in our regressions for simplicity.

\section{Stock Returns}

In our empirical analysis to capture the spillover effects from telecom liberalization we use stock market returns. Stock returns are constructed from MSCI Gross Total Return Index (TRI) for each country denominated in US dollars. These are daily stock returns based on general market price indices taken from Bloomberg, and then averaged over a calendar month. The stock return is the monthly difference of logarithm of the deflated MSCI TRI: $\log \left(\frac{R_{t}}{C P I_{t}}\right)-\log \left(\frac{R_{t-1}}{C P I_{t-1}}\right)$, where $R_{t}$ is the MSCI TRI for a country in time $t$, and $C P I_{t}$ is the US CPI during the same period. We have also constructed the same index for the world to be used as benchmark in our regressions.

\section{Empirical analysis}

In this section, we present the specification of our empirical analysis, the main results and robustness analysis.

\section{III.1 Specification}

In this sub-section, we present the empirical specification to explore the role of policies and institutional framework in driving the pace of telecom technology adoption. We do so within a framework of crosscountry panel regressions, specifically with an interaction term of liberalization and regulatory independence. The specification is as follows:

$$
y_{c t}=\beta_{0}+\beta_{1} l i b_{c t-1}+\beta_{2} \text { reg g }_{c t-1}+\beta_{3}\left(l i b_{c t-1} \times r e g_{c t-1}\right)+\beta_{4} X_{c t}+\beta_{5} G_{c t}+\mu_{c}+v_{t}+\varepsilon_{c t}
$$

where $y_{c t}$ is dependent variable. The dependent variable is the opposite of ranking which constitutes our technology adoption score. This score ranges from -198 to -1 , and the higher score the faster a country adopts new technology. $l i b_{c t-1}$ is a dummy variable that takes the value of one in the years after liberalization and zero otherwise, as discussed in Section II. We use the lagged liberalization to capture the effect of liberalization in the year before on technology adoption. reg $_{c t-1}$ is the score of telecom sector regulation in the previous period, and captures the effect of a more capable regulatory authority one year before the standard adoption. Our main variable of interest is the interaction between the two variables, 
$l i b_{c t-1} \times r e g_{c t-1}$, in order to investigate how the complementarities between liberalization and regulatory independence affect technology adoption in the next period.

The empirical model encompasses different panel specifications. The vector $X_{c t}$ denotes possible inclusion of time-varying country-level covariates, $G_{c t}$ denotes the technology generation fixed effect, and $\mu_{c}$ and $v_{t}$ are country and time fixed effects, respectively. The technology generation fixed effect is included to capture different distances in technology spectrum, and thus different difficulties to encounter in adopting different generations of telecom technology. And the country and time fixed effects capture, respectively, country and time specific factors that affect technology adoption.

We further explore the impact of foreign participation and regulation on technology adoption. We do so by replacing the liberalization in equation (1) with foreign participation, and the interaction term of foreign participation and regulatory independence to capture the effect of foreign participation after liberalization on technology adoption.

Next, we explore the relationship of technology adoption in telecom sector and stock returns. We do so with a cross-country panel regression of monthly stock market performance on technology adoption. The magnitude and statistical significance of stock market returns during the liberalization window are evaluated by estimating the following panel regression:

$$
R_{c t}=\beta_{0}+\beta_{1} \text { adptwin }_{c t}+\gamma_{1} R_{c t-1}+\gamma_{2} R_{t}^{\text {World }}+\gamma_{3} F_{c t}+\mu_{c}+\varepsilon_{c t}
$$

where the dependent variable $R_{c t}$ is the stock market return, measured by the log difference of CPI deflated monthly average of daily index of MSCI Gross Total Return, as discussed in Section II. Our main variable of interest adptwin $c$ indicates the event of technology adoption, and takes value of one in each of the eight months from $\mathrm{T}^{*}-7$ to $\mathrm{T}^{*}$ associated with country $c$ 's telecom technology adoptions. Hence, this variable captures the average change in monthly stock market performance during the eight-month technology adoption window. $R_{t}^{\text {World }}$ is the world stock returns during the same month, introduced as a benchmark control variable that changes over time. Following Henry (2000), we have also added macroeconomic fundamentals $F_{c t}$ to control for expected future cash flows. The macroeconomic fundamental variables include monthly growth rate of exchange rate, consumer price index, and political risk rating, respectively, in period $\mathrm{t}-1, \mathrm{t}$, and $\mathrm{t}+1 . \mu_{c}$ is the country fixed effects, and $\varepsilon_{c t}$ is a country- and time-specific error term.

To avoid potential endogeneity of technology adoption, we have further explored the relationship between technology adoption and stock market returns, with the technology adoption window in equation (2) instrumented by lagged liberalization, lagged telecom sector regulation score, and their interactions.

\section{III.2 Baseline regression results}

In this sub-section we present our main results.

The regression results in Table 1 show the importance of the complementarity between liberalization and the independence of the telecom regulatory authority - captured by the interaction term - in driving faster pace of technology adoption in telecom. ${ }^{7}$ The liberalization dummy is based on change in policy described in the data section. Instead, taken individually the coefficient associated with liberalization and regulatory independence are either not statistically significant or not robust over the different specification. Table 1 reports the estimated coefficients along with their robust standard errors. All regressions control for country

\footnotetext{
${ }^{7}$ Appendix Table 3 shows the list of countries used in Table 1 of the main text.
} 
fixed effects, columns (2) and (3) also control for year-fixed effects, and column (4) controls for the fixed effect of the generation of the technology standard adopted.

Column (1) indicates that the interaction term is positive and statistically significant. The result from column (1) is robust to controlling for both country and year fixed effects as shown in column (2). The coefficient in column (2) is indeed higher coefficient than column (1). The coefficient associated with the interaction term of 19.34 implies that for a country which has liberalized its telecom sector, an increase by one standard deviation of 0.3 in the regulatory score can boost technology adoption score by 2 in the ranking.

Columns (3) and (4) control for the logarithm of population and logarithm of gross domestic product (GDP) per capita. The coefficients associated with these control variables appear highly significant and with positive signs indicating they are associated with a higher pace of technology adoption. Column (3) confirm that the interaction term associated with liberalization and regulatory independence is significant economically and statistically. As we further introduce the fixed effect associated with the generation of technology standard adopted, the coefficient associated with the interaction term remains statistically significant at $10 \%$ level. Instead, the individual coefficient associated with liberalization and regulatory independence are not statistically significant. The coefficient associated with the interaction of 9.9 in column (4) indicates that, an improvement in regulatory score by 0.3 can boost technology adoption by 3 , i.e. outpacing 3 countries in the ranking of technology adoption. All in all, the complementarity between liberalization and regulatory independence appear robust in driving the pace of technology adoption.

Table 1. Technology Adoption, Liberalization and Regulatory Independence

\begin{tabular}{lcccc}
\hline Dep. Variable & \multicolumn{4}{c}{ Technology adoption score } \\
\cline { 2 - 5 } & $(1)$ & $(2)$ & $(3)$ & $(4)$ \\
\hline Liberalization (t-1) & -0.314 & 0.0188 & -1.272 & -4.759 \\
& $(4.089)$ & $(4.043)$ & $(4.129)$ & $(3.680)$ \\
Regulatory Score (t-1) & $-16.82^{* * *}$ & $-11.93^{*}$ & -10.76 & -10.02 \\
& $(6.248)$ & $(6.607)$ & $(7.162)$ & $(6.170)$ \\
Liberalization (t-1) x Regulatory Score (t-1) & $16.61^{* *}$ & $19.34^{* * *}$ & $15.98^{* *}$ & $9.941^{*}$ \\
& $(6.655)$ & $(6.715)$ & $(7.054)$ & $(6.011)$ \\
Population (log) & No & No & Yes & Yes \\
GDP per capita (log) & No & No & Yes & Yes \\
Fixed effects & & & & \\
Country & Yes & Yes & Yes & Yes \\
Year & No & Yes & Yes & Yes \\
Technology Generation & No & No & No & Yes \\
Observations & 2325 & 2325 & 2283 & 2283 \\
R-squared & 0.804 & 0.805 & 0.807 & 0.842 \\
\hline Note Coeficient
\end{tabular}

Notes: Coefficient estimates from ordinary least squares regressions at the country-year level, based on annual data from 2004 to 2018. Robust standard errors are given in parentheses. ${ }^{*} \mathrm{p}<0.1,{ }^{* *} \mathrm{p}<0.05,{ }^{* * *} \mathrm{p}<0.01$. The dependent variable is the technology adoption score, where a higher number means a better ranking and faster in technology adoption. Liberalization is a dummy variable, measured as 0 before the year of liberalization and 1 on the year of liberalization and thereafter. Regulatory Score is an indicator between 0 and 1, where 1 indicates highest score in ICT regulatory authority. The main variable of interest in all columns are the regulatory score interacted with liberalization. Constants are included in all columns. Regression in column (1) controls for country fixed effects; regressions in column (2) to (4) control for both country and year fixed effects; while regression in column (4) controls for, in 
addition, the fixed effect of the generation of technology that was adopted. See Appendix Table 3 for the country list of the regression in column (1).

In Table 2 we present results using foreign participation to capture effective liberalization instead of the dummy for the (de jure) liberalization episode. ${ }^{8}$ Regressions results presented in column (1) to (4) in table 2 confirm the importance of the complementarity between liberalization and regulatory independence in driving the pace of technology adoption. The coefficient associated with the variable of interest that is foreign participation interacted with the regulatory score is positive and highly statistically significant at the 1 percent level in all four columns.

Results presented in table 2 indicate that taken individually foreign participation per se does not foster technology adoption. In all columns, the individual effect of foreign participation and regulatory independence are negative and at time statistically significant in columns (1), (2) and (4). Only when combined with regulatory independence does foreign participation increase technology adoption.

The effect of the interaction is quantitatively large. Take for instance column (3) where for a country whose foreign participation is equal to the sample of average of 0.7 that is 70 percent of the market is owned by international operators, an increase in regulatory score by a standard deviation would boost the ranking in technology adoption by five notch, i.e. outpacing five peer countries in technology adoption. For a country with hundred percent market share owned by foreign operators, the impact of an improvement in regulatory score would obviously be even larger. An increase in regulatory score by a standard deviation would boost the technology ranking by seven, thus outpacing seven peer countries in the ranking of technology adoption. Regression results presented in column (4) shows a negative effect of foreign participation in technology adoption, while only a strong regulation can turn the effect of foreign participation into a net positive.

${ }^{8}$ Appendix Table 4 shows the list of countries used in the Table 2 of the main text. 
Table 2. Technology Adoption, Foreign participation and Regulatory Independence

\begin{tabular}{lcccc}
\hline Dep. Variable & \multicolumn{3}{c}{ Technology adoption score } \\
\cline { 2 - 5 } & $(1)$ & $(2)$ & $(3)$ & $-7.856^{*}$ \\
\hline Foreign Participation (t-1) & -2.557 & -1.544 & -5.605 & $(4.753)$ \\
Regulatory Score (t-1) & $(5.589)$ & $(5.696)$ & $(5.736)$ & $-15.37^{* * *}$ \\
& $-15.02^{* * *}$ & $-11.20^{*}$ & -10.55 & $(5.704)$ \\
Foreign Participation (t-1) x Regulatory Score (t-1) & $(5.792)$ & $(6.329)$ & $(6.658)$ & $23.88^{* * *}$ \\
& $24.71 * * *$ & $26.16^{* * *}$ & $24.42^{* * *}$ & $(6.682)$ \\
Population (log) & $(7.940)$ & $(8.015)$ & $(8.101)$ & Yes \\
GDP per capita (log) & No & No & Yes & Yes \\
Fixed effects & No & No & Yes & Yes \\
Country & & Yes & Yes & Yes \\
Year & Yes & Yes & Yes & Yes \\
Technology Generation & No & No & No & 2598 \\
Observations & No & 2679 & 2598 & 0.851 \\
R-squared & 2679 & 0.801 & 0.810 & .
\end{tabular}

Notes: Coefficient estimates from ordinary least squares regressions at the country-year level, based on annual data from 2004 to 2018. Robust standard errors are given in parentheses. ${ }^{*} \mathrm{p}<0.1,{ }^{* *} \mathrm{p}<0.05,{ }^{* * *} \mathrm{p}<0.01$. The dependent variable is the technology adoption score, where a higher number means a better ranking and faster in technology adoption. Foreign participation is internationally owned market share, calculated by the product of its market share and its share of ownership that is owned internationally. Regulatory Score is an indicator between 0 and 1 , where 1 indicates highest score in ICT regulatory authority. The main variable of interest in all columns are the regulatory score, interacted with foreign participation. Constants are included in all columns. Regression in column (1) controls for country fixed effects; regressions in column (2) to (4) control for both country and year fixed effects; while regression in column (4) controls for, in addition, the fixed effect of the generation of technology that was adopted. See Appendix Table 4 for the country list of the regression in column (1).

In Table 3, we explore the relationship between technology adoption and stock market returns using monthly data. The technology adoption window is a dummy variable for the event window of the adoption of a new standard in telecom technology following the empirical strategy used for capital account liberalization by Henry (2000). The event window begins seven months prior to the adoption month and ends in the adoption month. To fix ideas for a technology adopted in September 2005, the event window begins in February 2005 and ends in September 2005.

Country fixed effects are introduced in all regressions. Column (1) controls only for country fixed effects. A lagged dependent variable is introduced in columns (2) to (4). A variable capturing world stock returns is introduced in column (3)-(4) as a benchmark. It measures average stock market movements during the month. Following Henry (2000), macroeconomic fundamentals are also introduced in the last column, and includes monthly growth rate of exchange rate, consumer price index, and political risk rating, respectively, in period $t-1$, $\mathrm{t}$, and $t+1$.

Columns (1) to (4) show a statistically significant relationship between technology adoption and stock market returns. This is true even after controlling for world stock returns and lagged dependent variable. The impact is statistically significant and robust across the columns. Adopting a new generation of 
technology is associated with a 0.5 percent increase in stock returns for at least seven months everything else being equal.

Table 3.OLS: Stock returns and Technology Adoption

\begin{tabular}{lcccc}
\hline Dep. Variable & \multicolumn{4}{c}{ Stock Returns } \\
\cline { 2 - 5 } & $(1)$ & $(2)$ & $(3)$ & $(4)$ \\
\hline Technology Adoption Window & $0.00362^{* *}$ & $0.00313^{* *}$ & $0.00497^{* * *}$ & $0.00473^{* * *}$ \\
& $(0.00156)$ & $(0.00151)$ & $(0.00125)$ & $(0.00144)$ \\
World Stock Returns & & & $0.964^{* * *}$ & $0.980^{* * *}$ \\
& & & $(0.0143)$ & $(0.0158)$ \\
Country Fixed Effects & Yes & Yes & Yes & Yes \\
Lag Dependent & No & Yes & Yes & Yes \\
Macro Fundamentals & No & No & No & Yes \\
Observations & 17320 & 17270 & 17270 & 11424 \\
R-squared & 0.00187 & 0.0473 & 0.361 & 0.428 \\
\hline
\end{tabular}

Notes: This table presents coefficients from OLS regressions. The regressions are performed using stock market data from February 1980 to November 2019. Dependent is based on monthly average of daily index of MSCI Gross Total Return denominated in US dollars: $\log \left(\frac{R_{t}}{C P I_{t}}\right)-\log \left(\frac{R_{t-1}}{C P I_{t-1}}\right)$, where $R_{t}$ is the MSCI Gross Total Return in local market at time $t$, and $C P I_{t}$ is the consumer price index at the same period. Technology adoption window is a dummy variable for the event window of the adoption of a new generation in telecom technology. The event window begins seven months prior to the adoption month and ends in the adoption month. Constants are included in all columns. A lagged dependent variable is introduced in column (2) to (4) to reduce the occurrence of autocorrelation. World stock returns is introduced as benchmark control variables in column (3) to (4), based on monthly average of daily return of MSCI Total Return Index of World. Macroeconomic fundamentals are introduced in column (4), that includes monthly growth rate of exchange rate, consumer price index, and political risk rating, respectively, in period $t-1, t$, and $t+$ 1. All regressions control for country fixed effects. Robust standard errors in parentheses. ${ }^{*}, * *$ and $* * *$ denote significance at $10 \%, 5 \%$, and $1 \%$, respectively.

In Table 4, we instrument the technology adoption window with instruments consisting in liberalization, regulatory score, and their interaction, similarly to the right-hand side variables used in Table 1 . The instrumental variable regression (IV) allows us to ascertain the causal relationship going from technology adoption to stock returns. Appendix Table 5 shows the first stage of the IV regression indicating the instruments used in the regression are strong. Columns (1) to (4) indicate that adoption of latest technology standard cause a significant increase in stock returns. The coefficient in column 4 in Table 3 is over ten times higher than the one presented in column 4 in Table 3 . The causal effect thus appears much larger than the one obtained using ordinary least square. 
Table 4. Instrumental Variable Regressions: Technology Adoption and Stock Returns

\begin{tabular}{lcccc}
\hline Dep. Variable & \multicolumn{4}{c}{ Stock Returns } \\
\cline { 2 - 5 } & $(1)$ & $(2)$ & $(3)$ & $(4)$ \\
\hline Technology Adoption Window & $0.129^{* * *}$ & $0.0880^{* * *}$ & $0.0619^{* * *}$ & $0.0660^{* * *}$ \\
& $(0.0207)$ & $(0.0185)$ & $(0.0148)$ & $(0.0122)$ \\
World Stock Returns & & & $1.107^{* * *}$ & $1.093^{* * *}$ \\
& & & $(0.0198)$ & $(0.0221)$ \\
Country Fixed Effects & Yes & Yes & Yes & Yes \\
Lag Dependent & No & Yes & Yes & Yes \\
Macro Fundamentals & No & No & No & Yes \\
& & & & \\
Observations & 8700 & 8700 & 8700 & 6300 \\
R-squared & -0.377 & -0.0704 & 0.424 & 0.481 \\
\hline
\end{tabular}

Note: This table presents coefficients from instrumental-variables OLS regressions, where technology adoption window is instrumented, with excluded instruments being one-period lagged liberalization, oneperiod lagged regulatory score, and their interactions. Country fixed effects and constants are included each column. A lagged dependent variable is introduced in column (2) to (4) to reduce the occurrence of autocorrelation. World stock returns is introduced as benchmark control variables in column (3) to (4), based on monthly average of daily return of MSCI Total Return Index of World. Macroeconomic fundamentals are introduced in column (4), that includes monthly growth rate of exchange rate, consumer price index, and political risk rating, respectively, in period $t-1, t$, and $t+1$. Robust standard errors in parentheses. *, ** and $* * *$ denote significance at $10 \%, 5 \%$, and $1 \%$, respectively.

\section{III.3 Robustness and additional results}

In this sub-section, we present a few robustness checks and additional results. First, we use foreign direct investment in telecom as a share of total investment in the sector as a proxy for liberalization. Appendix Table 6 shows that the interaction between foreign direct investment-based measure of liberalization and regulatory independence drive the pace of technology adoption. Indeed, columns (1) to (4) shows that the coefficient associated with the interaction is statistically significant across the regressions. Taken separately foreign direct investment-based measure of liberalization and regulatory independence in columns (1) to (4) appear either negative or statistically insignificant. Whether we use the de jure measure of liberalization or effective measure of liberalization such as measures based on foreign participation and on foreign direct investment confirm our main results.

Additional robustness checks include regressions exploring the relationship between stock returns and technology adoption controlling for informational technology (IT) stock sub-index returns. This allows us to test whether the technology adoption aggregate stock return could be driven exclusively by IT sector. Appendix Table 7 shows the robustness our main results that technology adoption is associated with an increase in stock returns even when controlling for IT sub-index. The coefficient associated with technology adoption is indeed statistically significant and positive. Appendix Table 8 presents the instrumental variable regressions also controlling for IT stock sub-index. Results confirm the causal 
relationship running from technological adoption to stock returns. ${ }^{9}$ Telecom technology adoption has thus spillover on stock returns beyond the IT sector.

To further explore the spillover effect of telecom technology standards on other stock sub-indices. Appendix Table 10 shows that technology adoption affect other sectors such as "financials", "industrials" and "health care". Appendix Tables 11-17 present individual tables with a variety of specification that help ascertain the robustness of spillovers of telecom technology adoption on the afore mentioned sectors using stock sub-indices. In addition, several columns indicate that the effect of telecom technology adoption and "materials" and "consumer staples" sectors. All in all, telecom technology adoption is associated with spillovers which are far ranging.

\section{Conclusion}

The paper investigated the pace of technology adoption in telecom technology post liberalization and its effect on stock returns using a new global panel dataset. Results are twofold. First, evidence points to the complementarity between telecom liberalization and regulatory independence in driving a sustained pace of technology adoption. Second, results show a positive and economically significant effects of telecom adoption on stock returns pointing to significant spillovers of telecom to the rest of the economy.

While the adoption of $5 \mathrm{G}$ standards is accelerating, we are the very onset of radical changes in the technology landscape with ramifications well beyond economics. The strategic rivalry between the US and China will likely lead to an effective breakup of the internet. Further research in the interplay between the geopolitics around 5G and its economic implications would shed light on how technology will matter differently going forward.

\footnotetext{
${ }^{9}$ Appendix Table 9 presents the first stage of the instrumental variable regression associated with the second stage presented in Appendix Table 8.
} 


\section{References}

Arezki,R. Yuting Fan, R., Nguyen H., 2019, “Technology Adoption and the Middle Income Trap. Lessons from the Middle East and East Asia", World Bank Policy Research Working Paper, 8870, The World Bank.

Bekaert, Geert and Campbell R. Harvey. 2000. "Foreign Speculators and Emerging Equity Markets," Journal of Finance, 55(2), 565-613.

Bekaert, Geert, Campbell Harvey and Christian Lundblad. 2005. "Does Financial Liberalization Spur Growth?" Journal of Financial Economics, 77(1), 3-55.

Barro, Robert J \& Sala-i-Martin, Xavier, 1997. "Technological Diffusion, Convergence, and Growth," Journal of Economic Growth, Springer, vol. 2(1), pages 1-26, March.

Talal Ahmad and Lakshminarayanan Subramanian. 2017. Virtual Cellular ISPs. In Proceedings of the 3rd Workshop on Experiences with the Design and Implementation of Smart Objects (SMARTOBJECTS '17). ACM, New York, NY, USA, 35-40. DOI: https://doi.org/10.1145/3127502.3127515

Bresnahan, T.F., and M. Trajtenberg (1996). “General purpose technologies: ‘engines of growth'?”, Journal of Econometrics, 65, 83-108

Cave, M (2018) “How disruptive is 5G?", Telecommunications Policy, Volume 42, Issue 8, 2018, Pages 653-658, ISSN 0308-5961, https://doi.org/10.1016/j.telpol.2018.05.005.

Cervellati, M., Naghavi, A. and F. Toubal (2018). "Trade Liberalization, Democratization and Technology Adoption”. Journal of Economic Growth, 23, p145-173.

Comin, D. and B. Hobijn, (2009a). "The CHAT Dataset", Harvard Business School Working Paper, 10.

Comin, D. and B. Hobijn (2009b). "Lobbies and Technology Diffusion". The Review of Economics and Statistics, 91(2), p229-244.

Comin, D. and B. Hobijn (2010). “An Exploration of Technology Diffusion”. American Economic Review, 100, p2031-2059.

R. H. Coase, “The Federal Communications Commission, 1959”, The Journal of Law \& Economics, Vol. 2, pp. $1-40$

Crandall, Robert W. 2019. "The Dubious Antitrust Argument for Breaking Up the Internet Giants." Review of Industrial Organization 54, no. 4: 627-49.

Egert, Balazs, "Infrastructure Investment in Network Industries: The Role of Incentive Regulation and Regulatory Independence (May 1, 2009)". CESifo Working Paper Series No. 2642. Available at SSRN: https://ssrn.com/abstract=1400615

Jamison, M. 2019, “Applying antitrust in digital markets: Foundations and approaches”, AEI Economics Working Paper 2019-18, available at: https://www.aei.org/wp-content/uploads/2019/11/Jamison-DigitalMarkets-WP.pdf

Furman, Jason, Diane Coyle, Amelia Fletcher, Derek McAuley, and Philip Marsden. 2019. "Unlocking Digital Competition: Report of the Digital Competition Expert Panel. London: UK Government Publications. 
Gomez, Marcela and Weiss, Martin B. H. and Lehr, William and McHenry, Giulia, Spectrum Valuation: Implications for Sharing and Secondary Markets (March 16, 2018). TPRC 46: The 46th Research Conference on Communication, Information and Internet Policy 2018. Available at SSRN: https://ssrn.com/abstract=3142182 or http://dx.doi.org/10.2139/ssrn.3142182

Harald Gruber, "Competition and innovation: The diffusion of mobile telecommunications in Central and Eastern Europe", Information Economics and Policy, Volume 13, Issue 1, 2001, Pages 19-34, https://doi.org/10.1016/S0167-6245(00)00028-7.

Harper C. and Deutsch, B. 2019, "Innovation,Verticals, and Beams: Importance of Time-Domain Mastery for 5G-and-Beyond”, Journal of ICT Standardization, vol 7. Issue, 2, https://doi.org/10.13052/jicts2245$800 X .727$

Haucap, J. \& Heimeshoff, Google, Facebook, Amazon, eBay: Is the Internet driving competition or market monopolization? U. Int Econ Econ Policy (2014) 11: 49. https://doi.org/10.1007/s10368-013-0247-6

Henry, Peter Blair. 2000. "Stock Market Liberalization, Economic Reform, and Emerging Market Equity Prices,” Journal of Finance, 55(2), 529-564.

Laffont, J.-J., Rey, P. and J. Tirole (1997). "Competition between Telecommunications Operators". European Economic Review, 41, p701-711.

Lee, 2019, Enabling opportunities: 5G, the internet of things, and communities of color, Brookings Institution, Washington, DC, https://www.brookings.edu/research/enabling-opportunities-5g-the-internetof-things-and-communities-of-color/

William Lehr, Lee W McKnight, "Wireless Internet access: 3G vs. WiFi?", Telecommunications Policy, Volume 27, Issues 5-6, 2003, Pages 351-370, ISSN 0308-5961, https://doi.org/10.1016/S03085961(03)00004-1. (http://www.sciencedirect.com/science/article/pii/S0308596103000041)

Lehr, William; Clark, David; Bauer, Steve (2019) : Regulation when platforms are layered, 30th European Conference of the International Telecommunications Society (ITS): "Towards a Connected and Automated Society", Helsinki, Finland, 16th-19th June 2019, International Telecommunications Society (ITS), Helsinki

Levy ad Spiller, 1994, "The Institutional Foundations of Regulatory Commitment: A Comparative Analysis of Telecommunications Regulation", The Journal of Law, Economics, and Organization, Volume 10, Issue 2, October 1994, Pages 201-246, https://doi.org/10.1093/oxfordjournals.jleo.a036849

M. Lotfi, and S. Sarkar, "The economics of competition and cooperation between MNOs and MVNOs," Information Sciences and Systems (CISS), 2017

Marja Matinmikko, Matti Latva-aho, Petri Ahokangas, Veikko Seppanen, 2018, "On regulations for 5G: Micro licensing for locally operated networks", Telecommunications Policy, 2018

Montes, R., Sand-Zantman, W., Valetti, T., 2018, “The Value of Personal Information in Online Markets with Endogenous Privacy”, Management Science, Vol. 65, No. 3

Nicolle, A., Grzybowski, L. and Zulehner, C. (2018), "Impact of Competition, Investment and Regulation on Prices of Mobile Services: Evidence from France", Economic Inquiry, 56: 1322-1345. doi:10.1111/ecin.12547 
Pasquali, R. Presentation "Introduction to 5G", given to the Order of Engineers at the Faculty of Engineering of the Polytechnic of Turin, on November $14^{\text {th }}, 2019$

Emanuel Puschita, Anca Constantinescu-Dobra, Rebeca Colda, Irina Vermesan, Ancuta Moldovan, Tudor Palade, 2014, "Challenges for a broadband service strategy in rural areas: A Romanian case study", Telecommunications Policy, Volume 38, Issue 2, 2014, Pages 147-156, https://doi.org/10.1016/j.telpol.2013.08.001.

Rohlfs, J. Jackson, C. and Kelly, T. (1991) “Estimate of the Loss to the United States caused by the FCC's delay in Licensing Cellular Telecommunications", National Economic Research Associates: White Plains.

Rossotto, CM Sekkat, K. , Varoudakis, A., 2005 "Opening up telecommunications to competition and MENA integration in the world economy", Journal of International Development

Rossotto, C. M., Lal Das, P., Gasol Ramos, E., Clemente Miranda, E., Badran, M. F., Martinez Licetti, M., \& Miralles Murciego, G. (2018). "Digital platforms: A literature review and policy implications for development". Competition and Regulation in Network Industries, 19(1-2), 93109. https://doi.org/10.1177/1783591718809485

Rosston, G. and Topper, M. (2010) "An antitrust analysis of the case for wireless network neutrality," Information Economics and Policy, Vol 22 No. 1. 103-119

Rosston G., (2012), "The Relationship between Technological and Regulatory Change in the Communications Industry", No 11-020, Discussion Papers, Stanford Institute for Economic Policy Research

Samdanis K., Costa-Perez X. and Sciancalepore V., "From network sharing to multi-tenancy: The 5G network slice broker," in IEEE Communications Magazine, vol. 54, no. 7, pp. 32-39, July 2016. doi: 10.1109/MCOM.2016.7514161

Sutherland, Ewan, Bribery and Corruption in Telecommunications - Best Practice in Prevention and Remedies (March 2, 2012). 2012 TRPC. Available at SSRN: https://ssrn.com/abstract=2014665or

Towhidul Islam, Nigel Meade, "The impact of competition, and economic globalization on the multinational diffusion of $3 \mathrm{G}$ mobile phones", Technological Forecasting and Social Change, Volume 79, Issue 5, 2012, Pages 843-850,

Venkata Praveen Tanguturi, Fotios C. Harmantzis, "Migration to $3 \mathrm{G}$ wireless broadband internet and real options: The case of an operator in India", Telecommunications Policy, Volume 30, Issue 7, 2006, Pages 400-419, https://doi.org/10.1016/j.telpol.2006.02.004.

Wallsten, 2001, "An econometric analysis of telecom competition, privatization, and regulation in Africa and Latin America”, The Journal of industrial economics

Wallsten, 2003, "An Econometric Analysis of Telecom Competition, Privatization, and Regulation in Africa and Latin America", The Journal of Industrial Economics, 2003, https://doi.org/10.1111/14676451.00135

Wallsten, Scott, Is There Really a Spectrum Crisis? Quantifying the Factors Affecting Spectrum License Value (January 23, 2013). Available at SSRN: https://ssrn.com/abstract=2206466 or http://dx.doi.org/10.2139/ssrn.2206466 
Waverman, Leonard, and Esen Sirel. 1997. "European Telecommunications Markets on the Verge of Full Liberalization." Journal of Economic Perspectives, 11 (4): 113-126.

Wellenius, B., \& Rossotto, C. M. (2000). Introducing Telecommunications Competition through a Wireless License: Lessons from Morocco. Journal of Network Industries, os-1(4), 469477. https://doi.org/10.1177/178359170000100404

Wheeler, T, 2019, 5G in five (not so easy) pieces, blog available at the Brookings Institution, website : https://www.brookings.edu/research/5g-in-five-not-so-easy-pieces/ 
Appendix. Table 1. List of variables and sources

\begin{tabular}{|l|l|l|}
\hline Variables & Description & Source \\
\hline Technology adoption score & The opposite of technology adoption ranking. & $\begin{array}{l}\text { Author's calculation based on launch date of } \\
\text { new technology from Telegeography }\end{array}$ \\
\hline Liberalization & Dummy variable of telecom sector's liberalization. & Telegeography \\
\hline Regulatory score & $\begin{array}{l}\text { Indicator between 0 and 1, where 1 indicates highest } \\
\text { score in ICT regulatory authority }\end{array}$ & International Telecommunication Union \\
\hline Market share & Percentage share of the total market connections. & GSMA Intelligence \\
\hline Ownership & Total economic interests. & GSMA Intelligence and authors' collection \\
\hline FDI & Capex FDI in communication sector ${ }^{10}$ in mUSD & Financial Times, fDi intelligence \\
\hline Total investment & $\begin{array}{l}\text { Annual investment in telecommunication services }{ }^{11} \text { in } \\
\text { mUSD }\end{array}$ & International Telecommunication Union \\
\hline Population & Population (million persons) & $\begin{array}{l}\text { International Monetary Fund, World Economic } \\
\text { Outlook Database }\end{array}$ \\
\hline PPP GDP & $\begin{array}{l}\text { Nominal gross domestic product in purchasing-power- } \\
\text { parity dollars (billions of PPP dollars) }\end{array}$ & $\begin{array}{l}\text { International Monetary Fund, World Economic } \\
\text { Outlook Database }\end{array}$ \\
\hline
\end{tabular}

${ }^{10}$ Communication sector includes subsectors of Communications equipment, Wireless telecommunication carriers, Data processing, hosting, \& related services, Wired telecommunication carriers, Radio \& TV broadcasting, Motion picture \& sound recording industries, Other telecommunications, Satellite telecommunications, Navigational instruments, Cable \& other subscription programming.

${ }^{11}$ Annual investment in telecommunication services refers to the investment during the financial year made by entities providing telecommunication networks and/or services (including fixed; mobile and Internet services; as well as the transmission of TV signals) for acquiring or upgrading fixed assets (usually referred to as CAPEX); less disinvestment owing to disposals of fixed assets. Fixed assets should include tangible assets; such as buildings and networks; and non-tangible assets; such as computer software and intellectual property. The definition closely corresponds to the concept of gross fixed capital formation; as defined in the System of National Accounts 2008. The indicator is a measure of investment made by entities providing telecommunication networks and/or services in the country; and includes expenditure on initial installations and additions to existing installations where the usage is expected to be over an extended period of time. It excludes expenditure on fees for operating licences and the use of radio spectrum. 
Appendix. Table 1. Continued

\begin{tabular}{|l|l|l|}
\hline Stock Index & MSCI Gross Total Return Index & Bloomberg \\
\hline World Stock Index & MSCI Gross Total Return Index & Bloomberg \\
\hline Stock returns & First difference of deflated stock index in logarithm & Derived from stock index \\
\hline IT Index & MSCI IT index & Bloomberg \\
\hline Energy Index & MSCI Energy Index & Bloomberg \\
\hline Financials Index & MSCI Financials Index & Bloomberg \\
\hline Materials Index & MSCI Materials Index & Bloomberg \\
\hline Industrials Index & MSCI Industrials Index & Bloomberg \\
\hline Consumer Staples Index & MSCI Consumer Staples Index & Bloomberg \\
\hline Health Care Index & MSCI Health Care Index & Bloomberg \\
\hline World IT Index & MSCI World IT Index & Bloomberg \\
\hline World Energy Index & MSCI World Energy Index & Bloomberg \\
\hline World Financials Index & MSCI World Financials Index & Bloomberg \\
\hline World Materials Index & MSCI World Materials Index & Bloomberg \\
\hline World Industrials Index & MSCI World Industrials Index & Bloomberg \\
\hline World Consumer Staples Index & MSCI World Consumer Staples Index & Bloomberg \\
\hline World Health Care Index & MSCI World Health Care Index & Bloomberg \\
\hline
\end{tabular}




\section{Appendix Figure 1. Evolution of Telecom Standard Adoption}
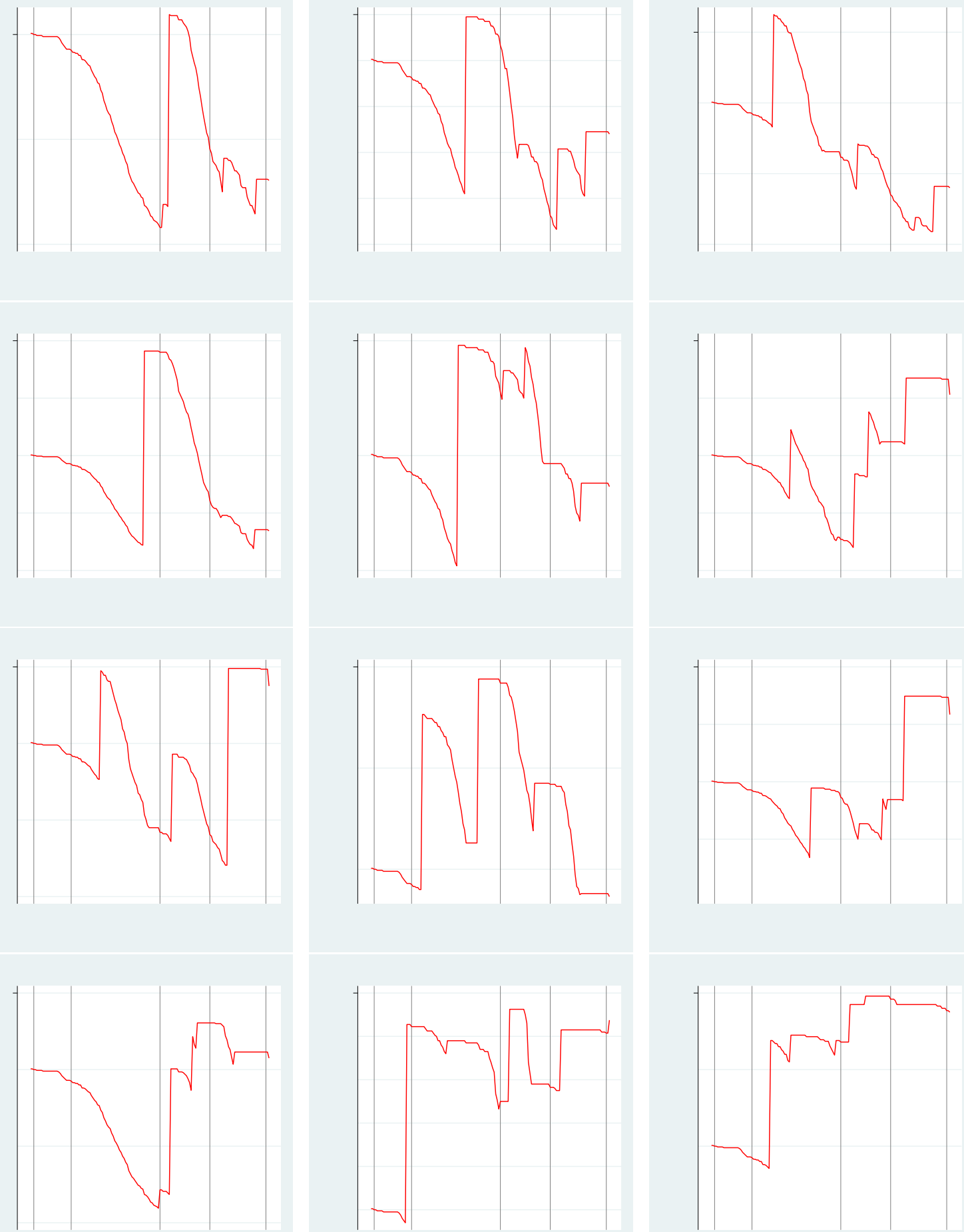

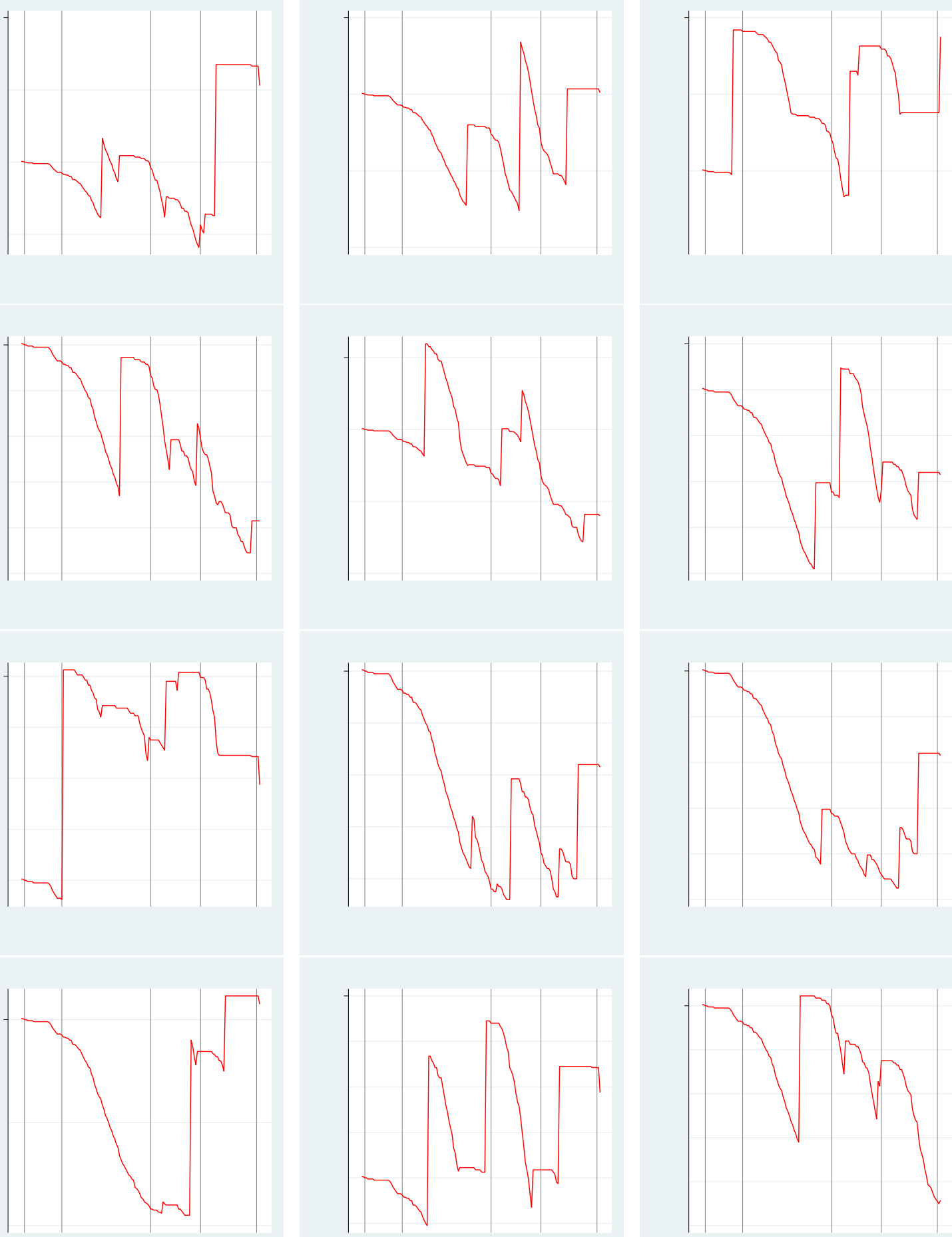

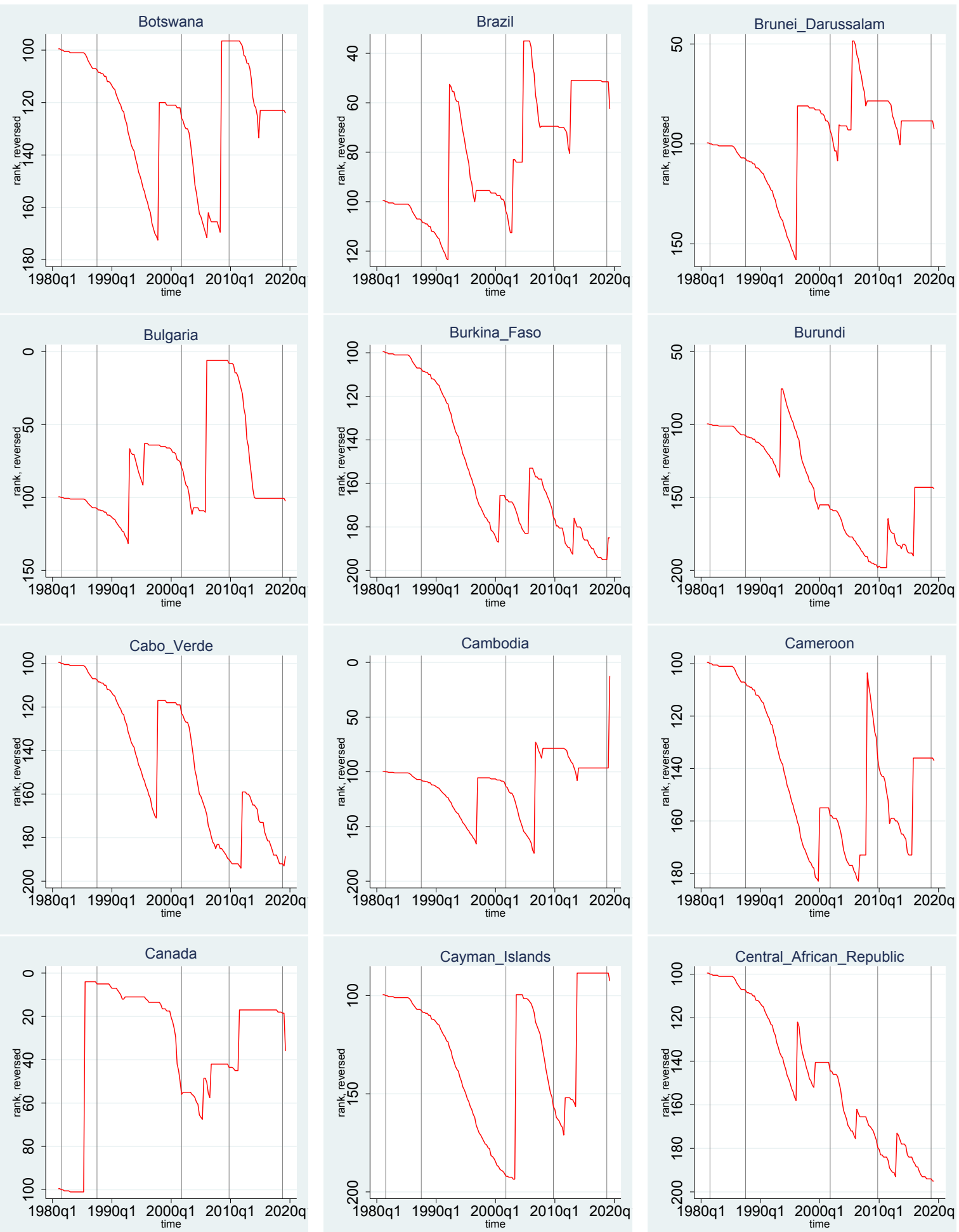

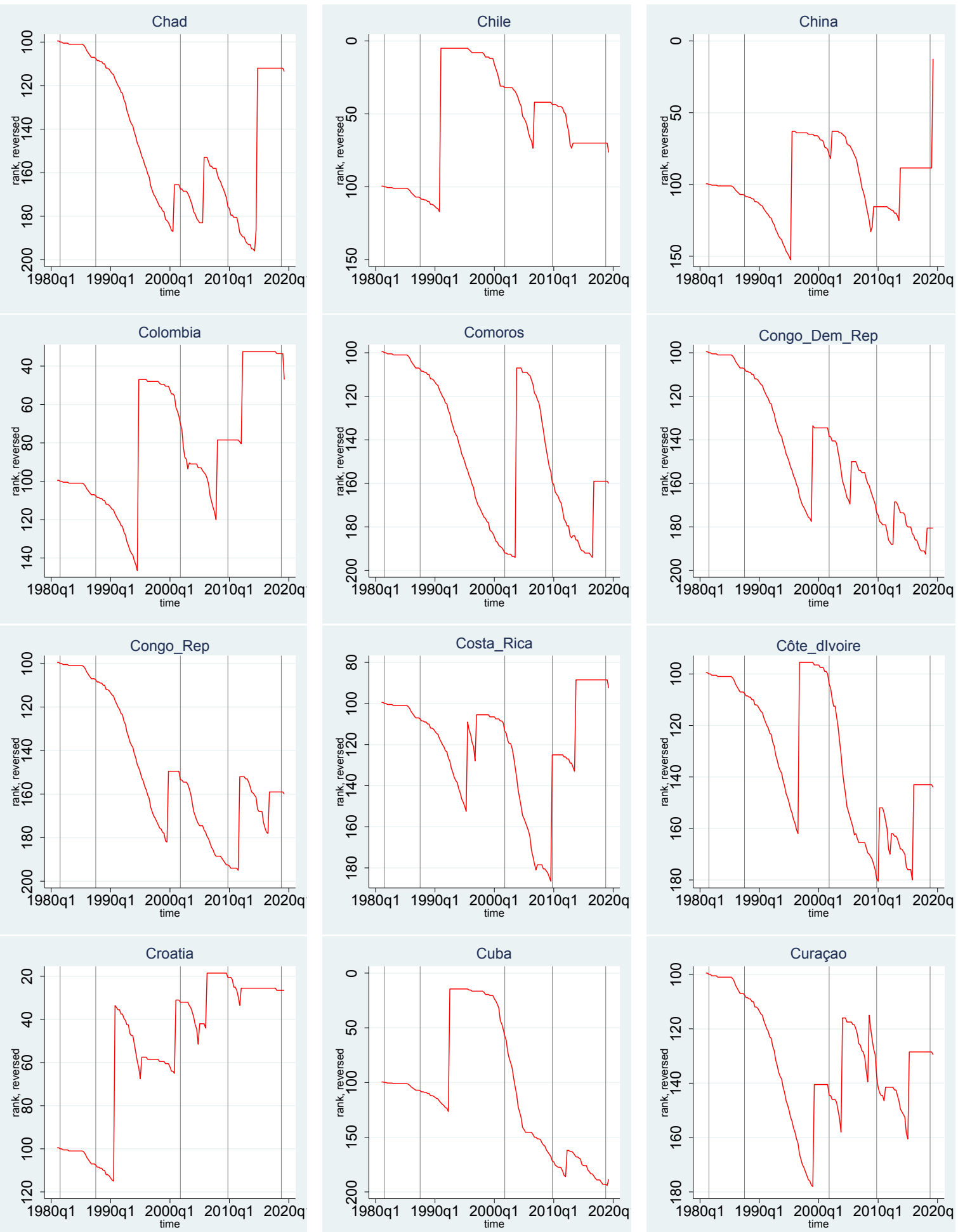

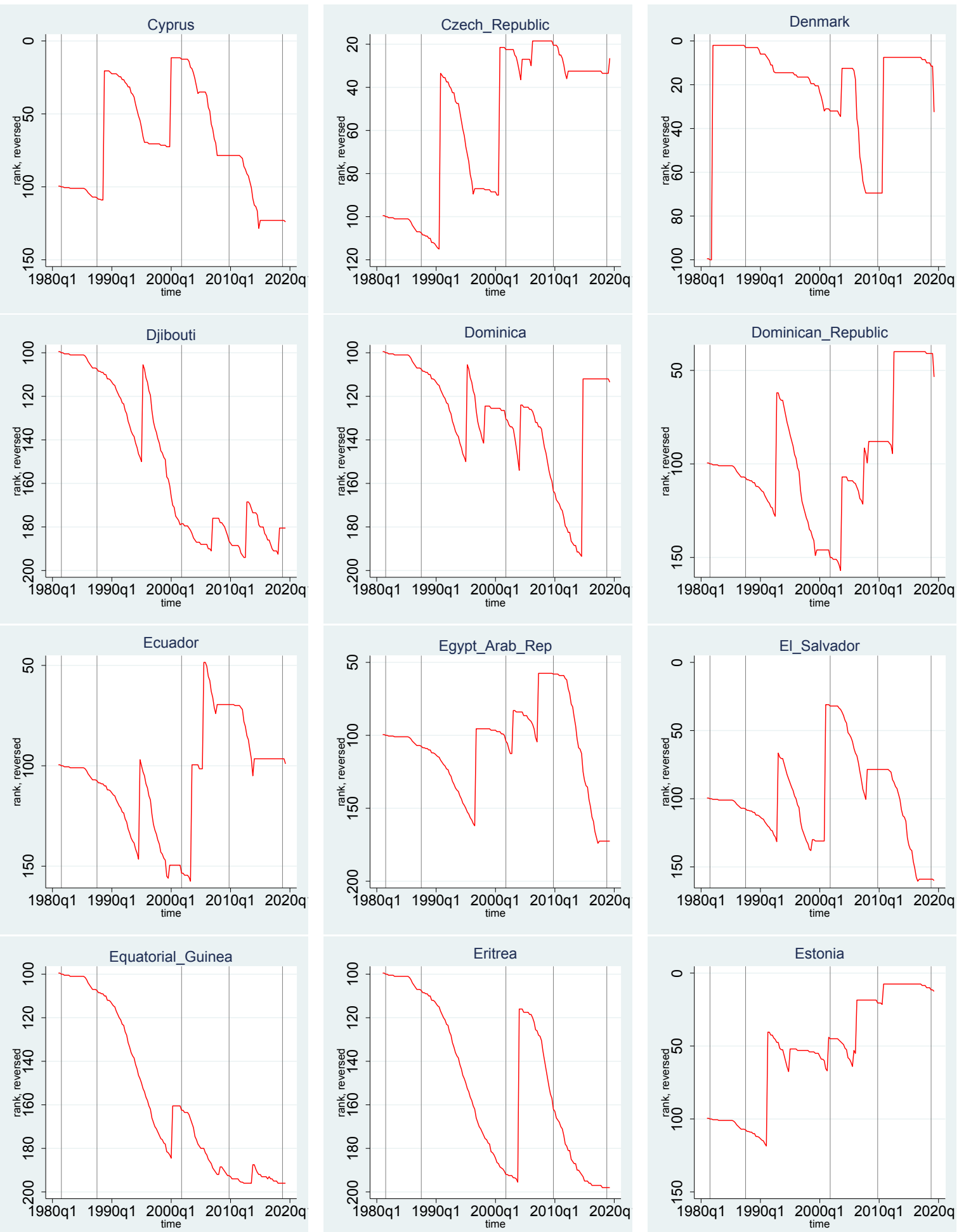

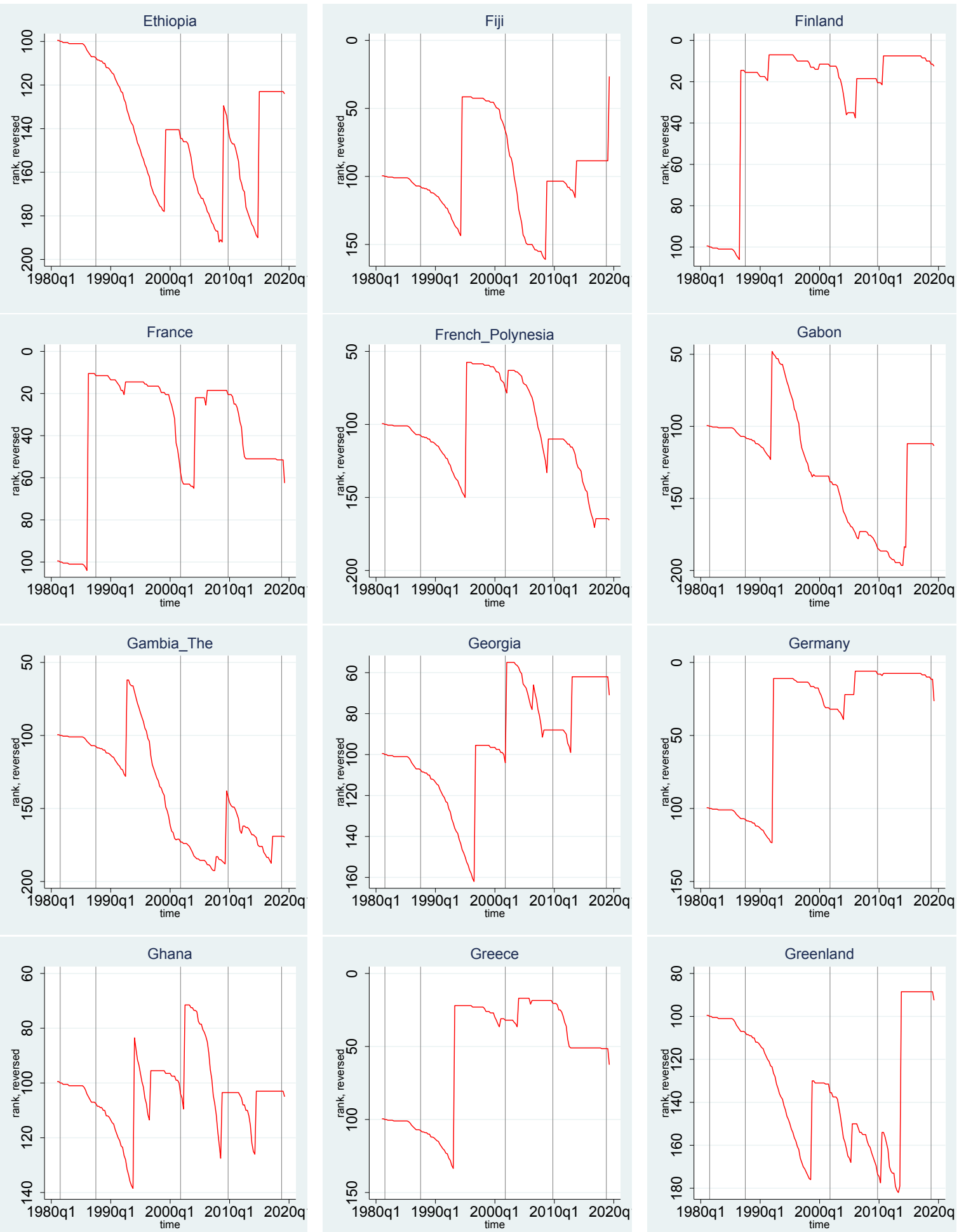

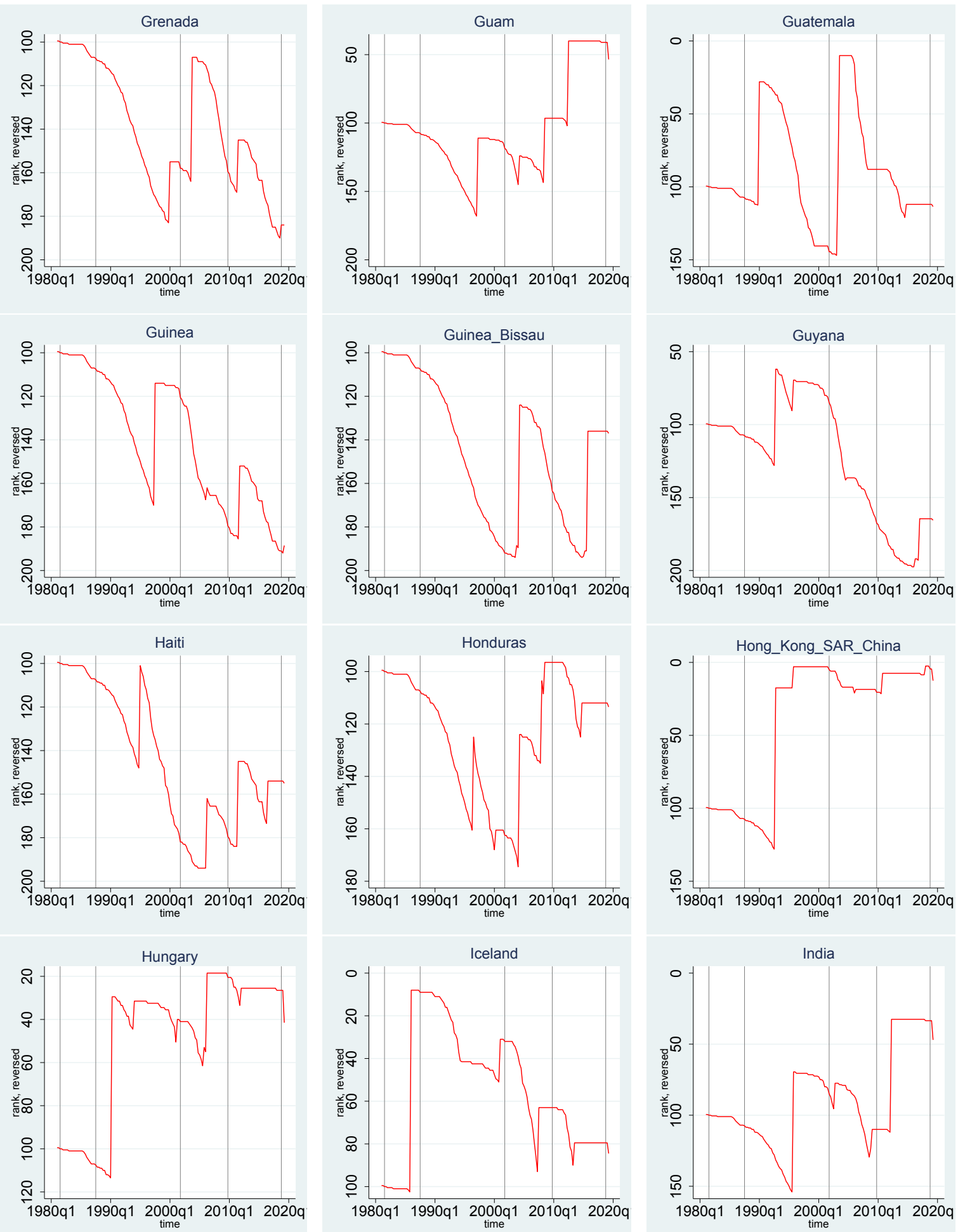

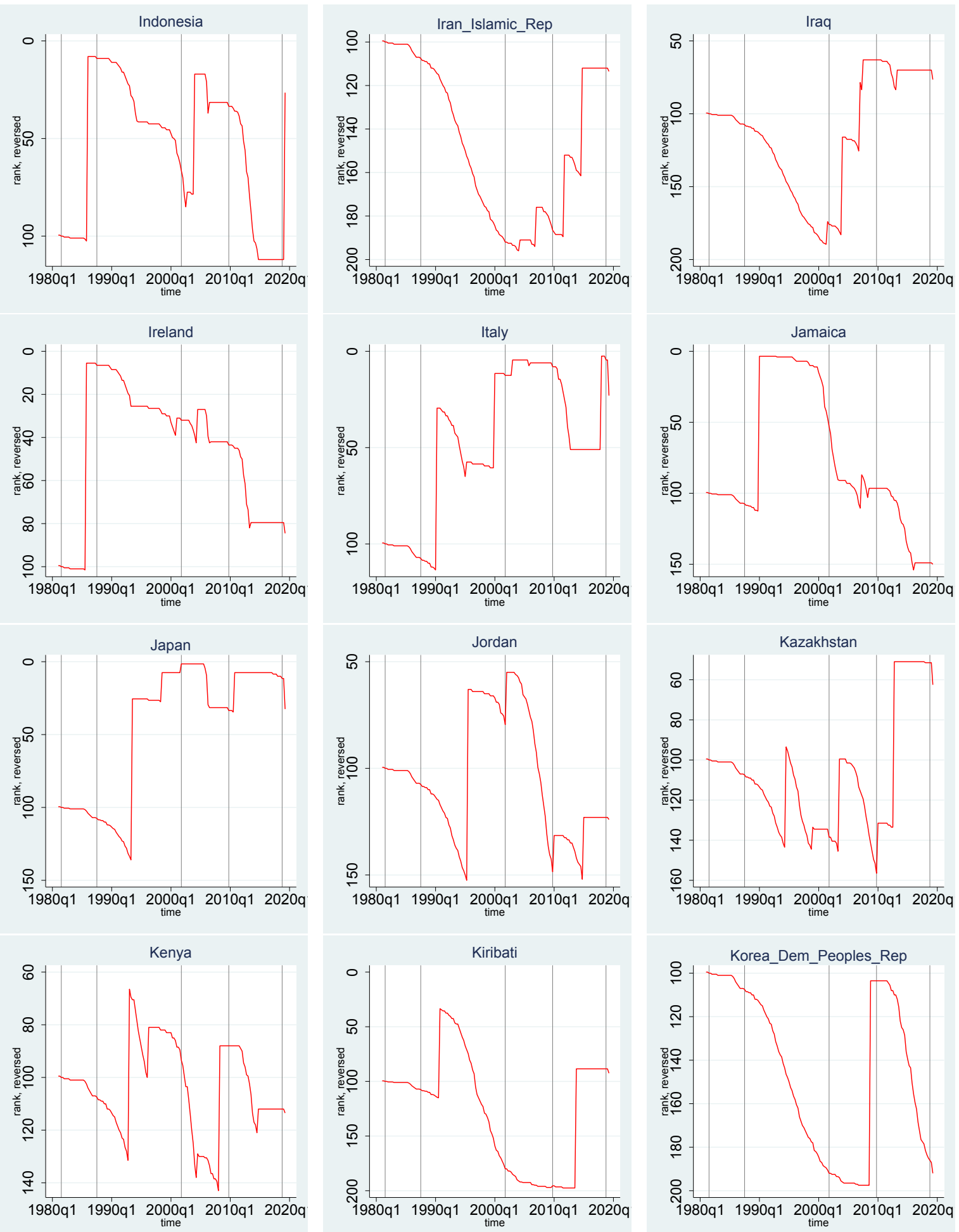

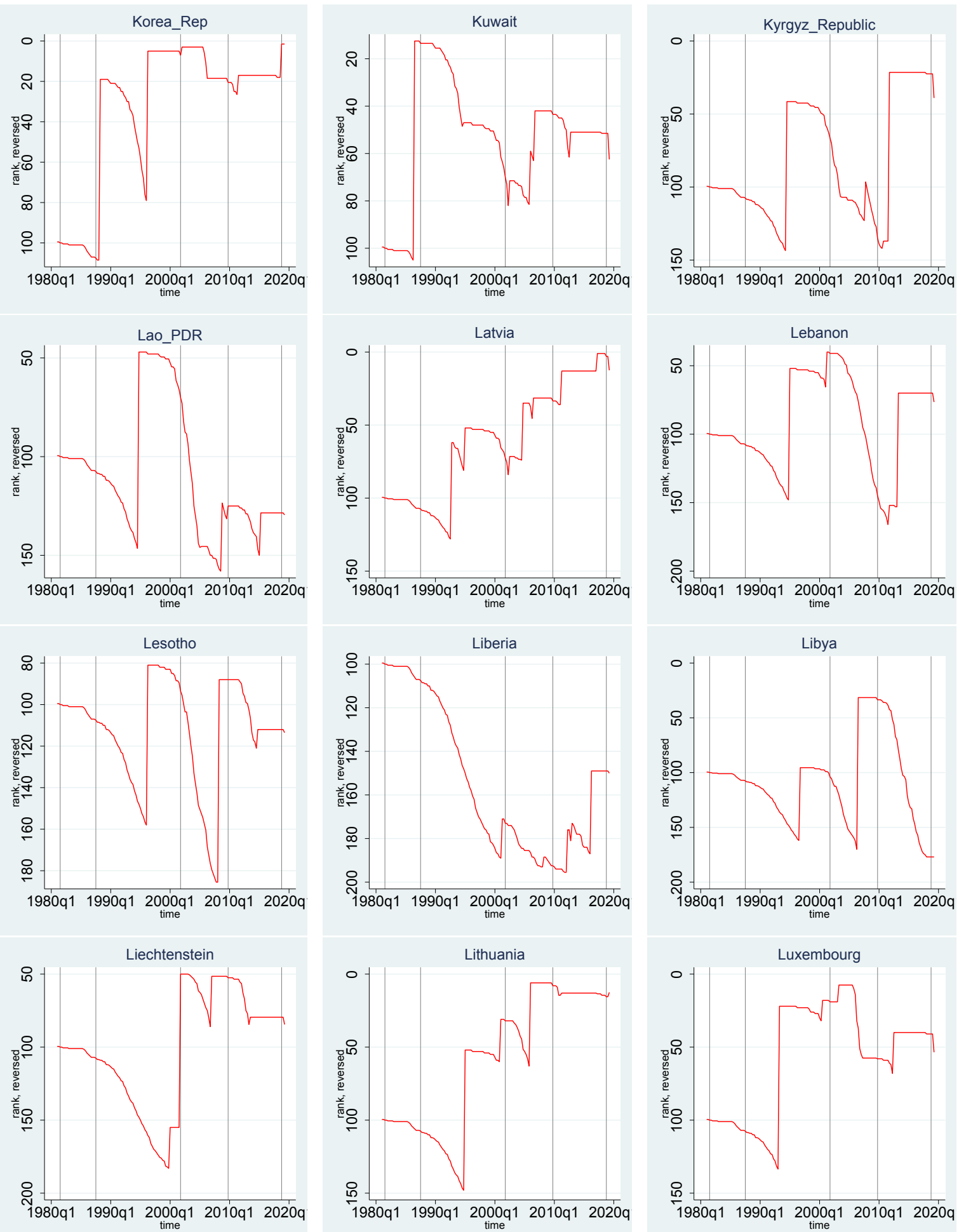

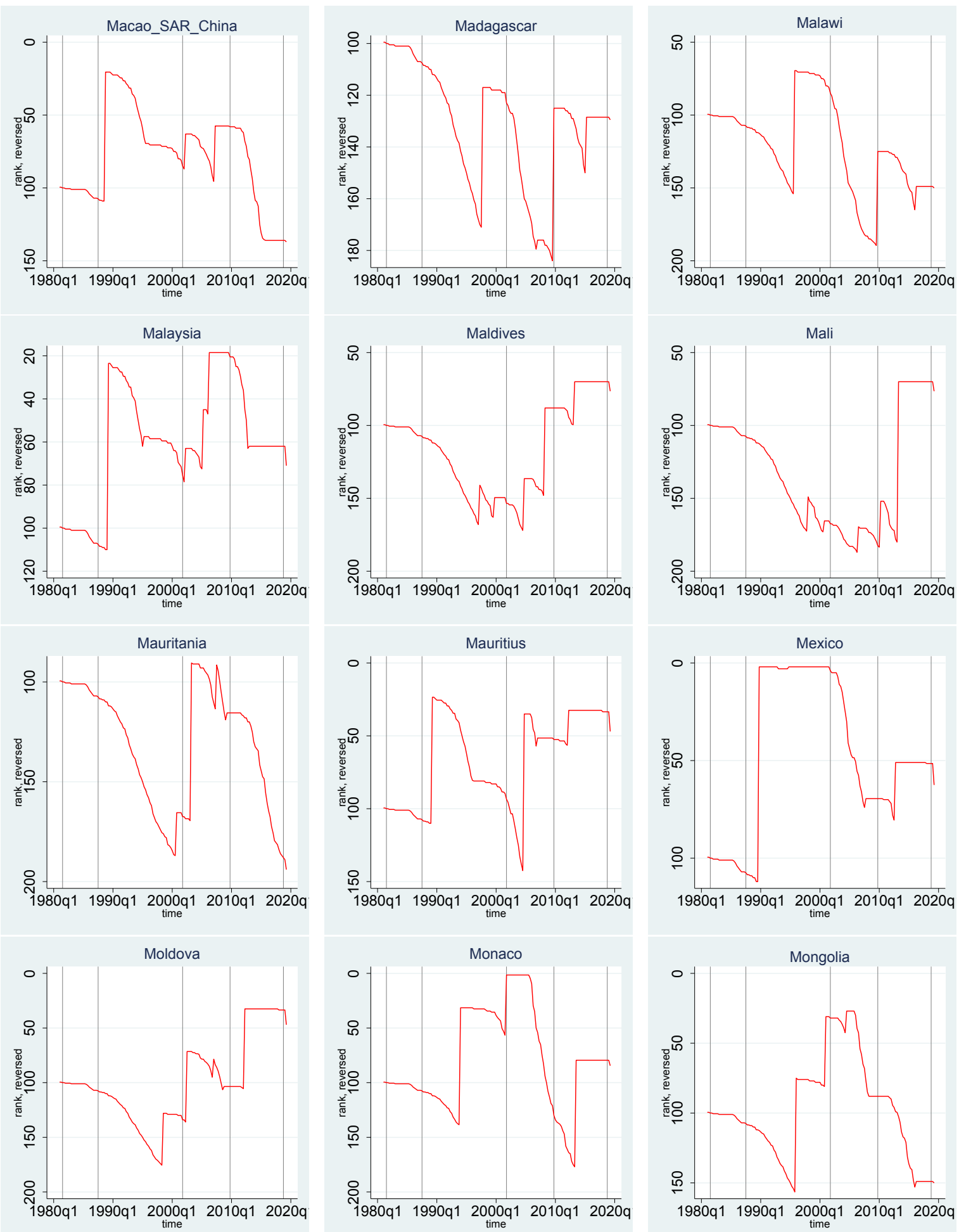

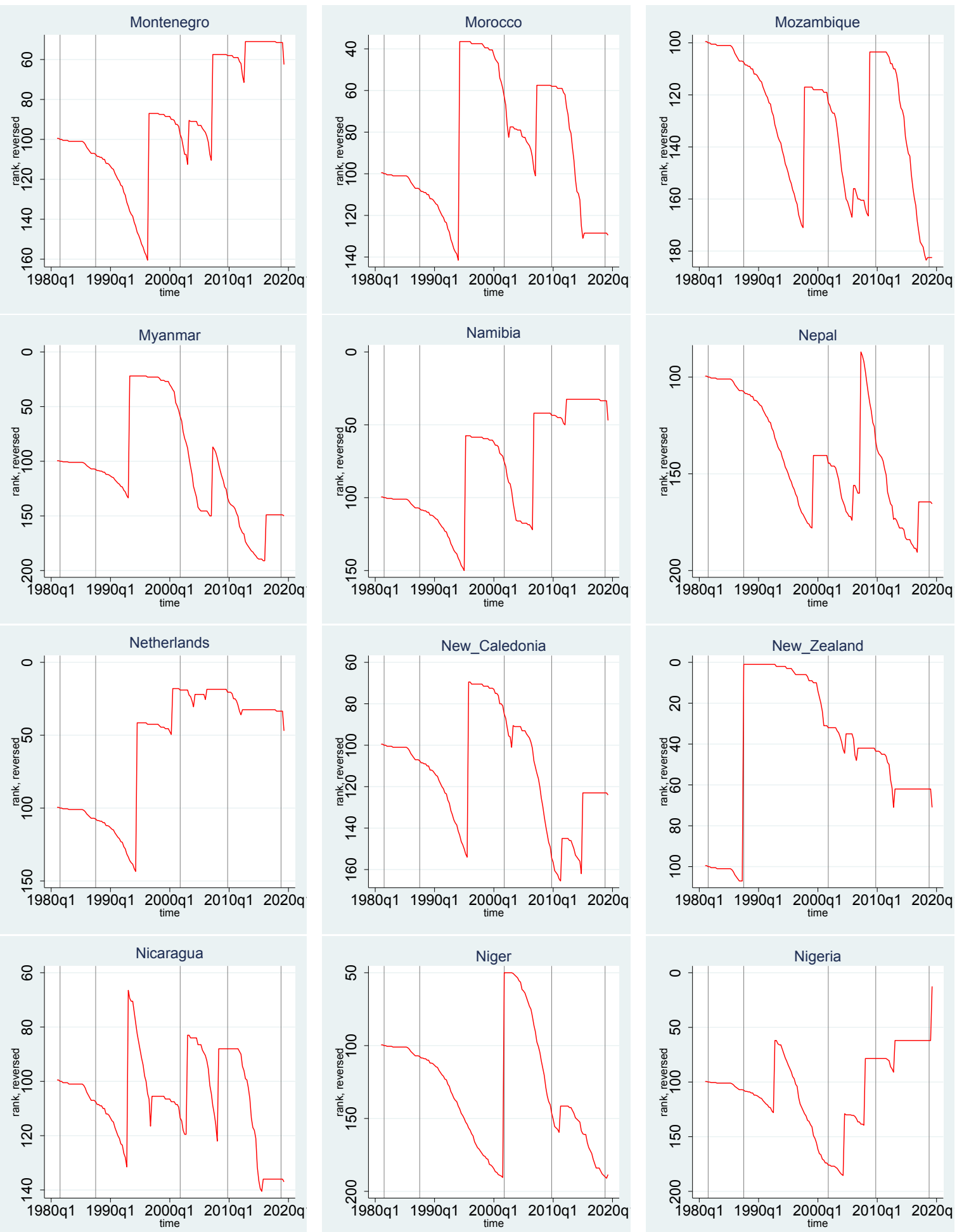

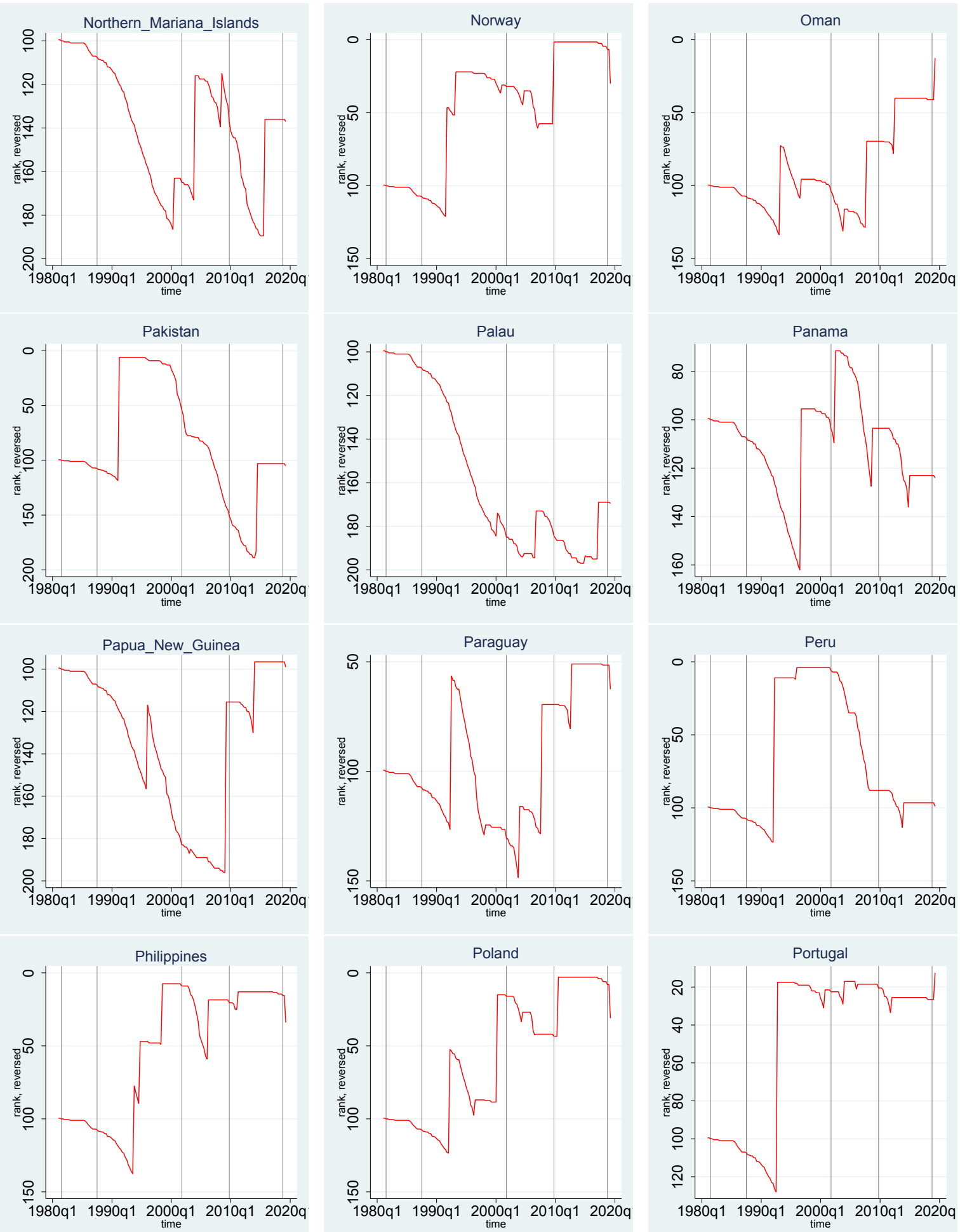

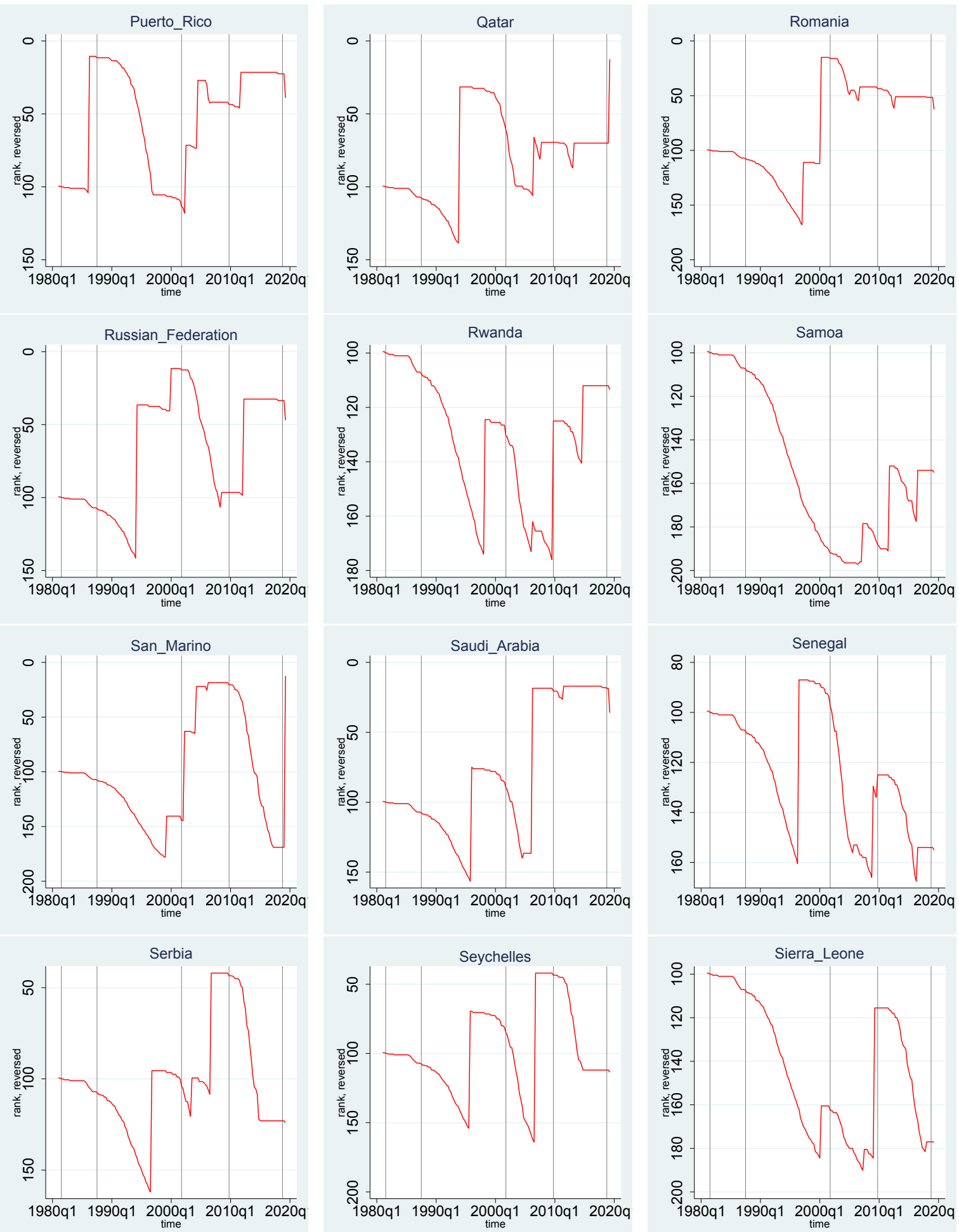

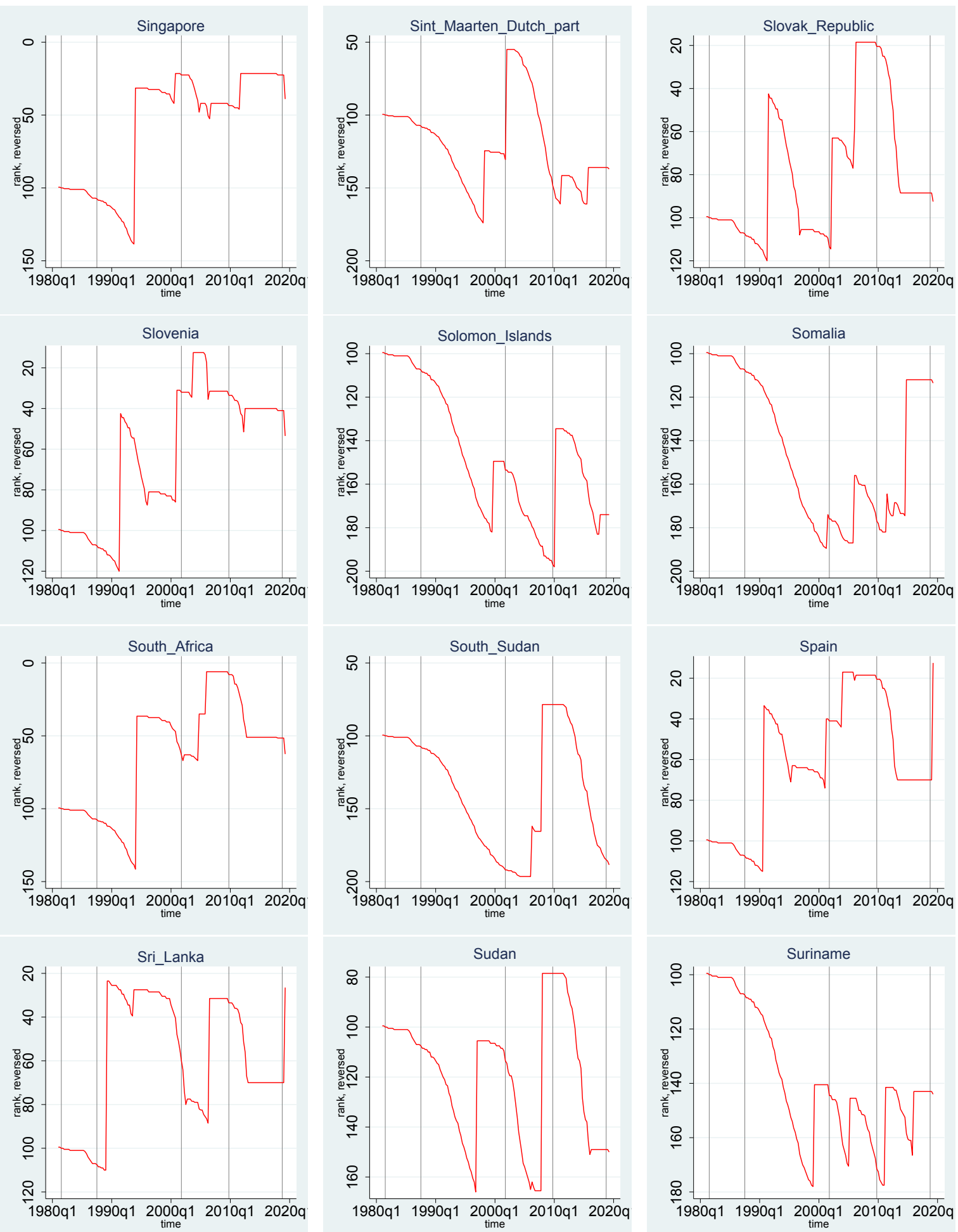

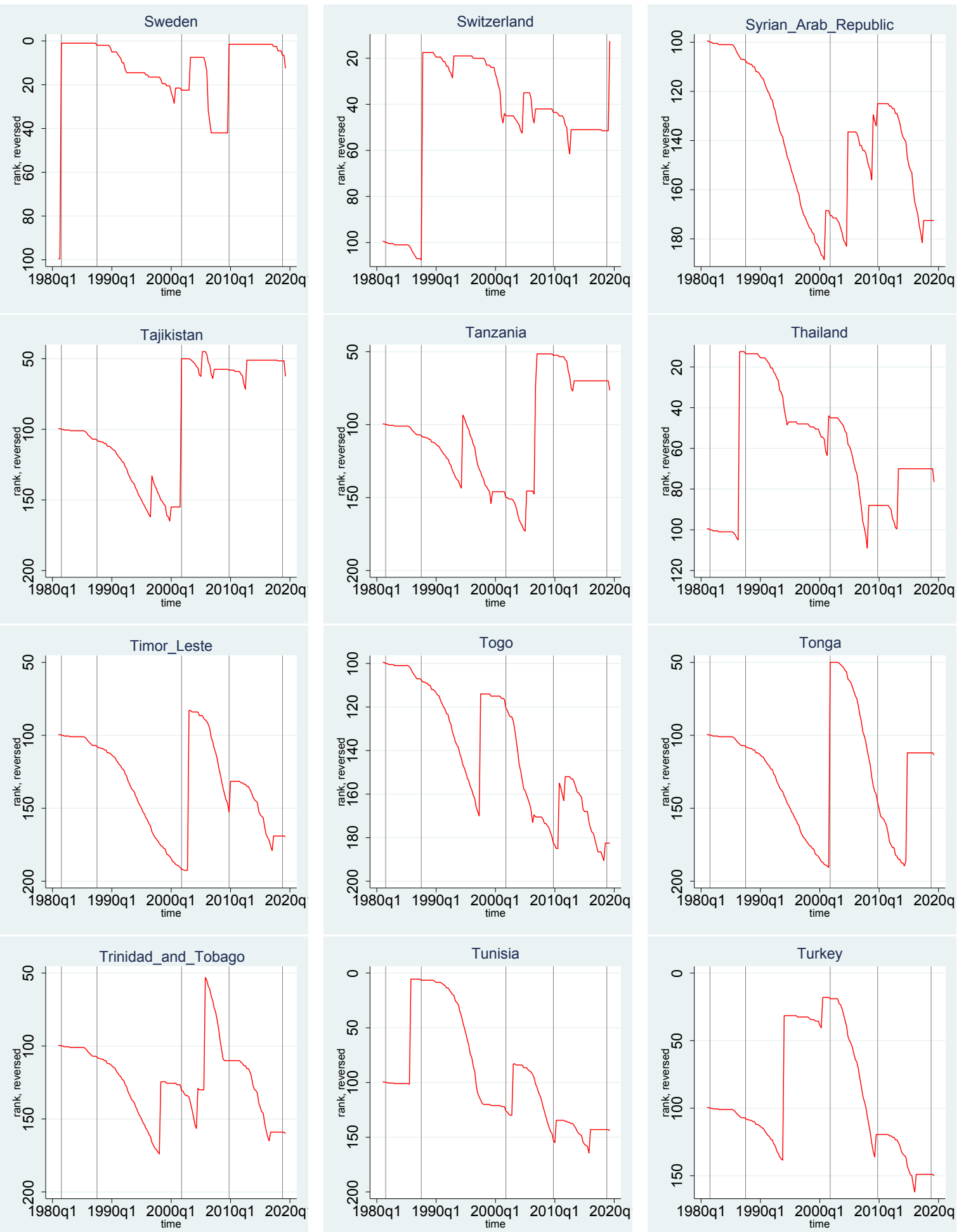

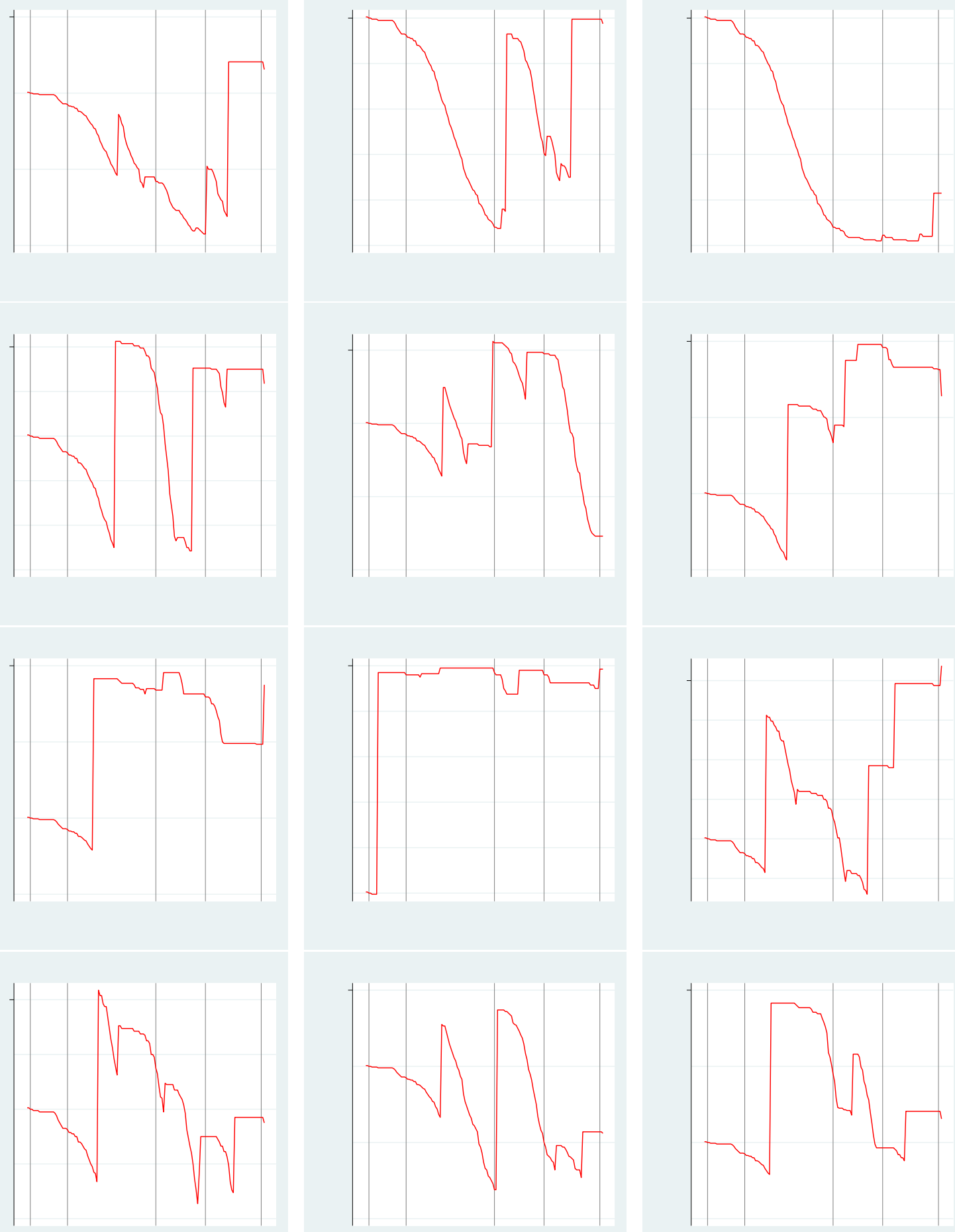

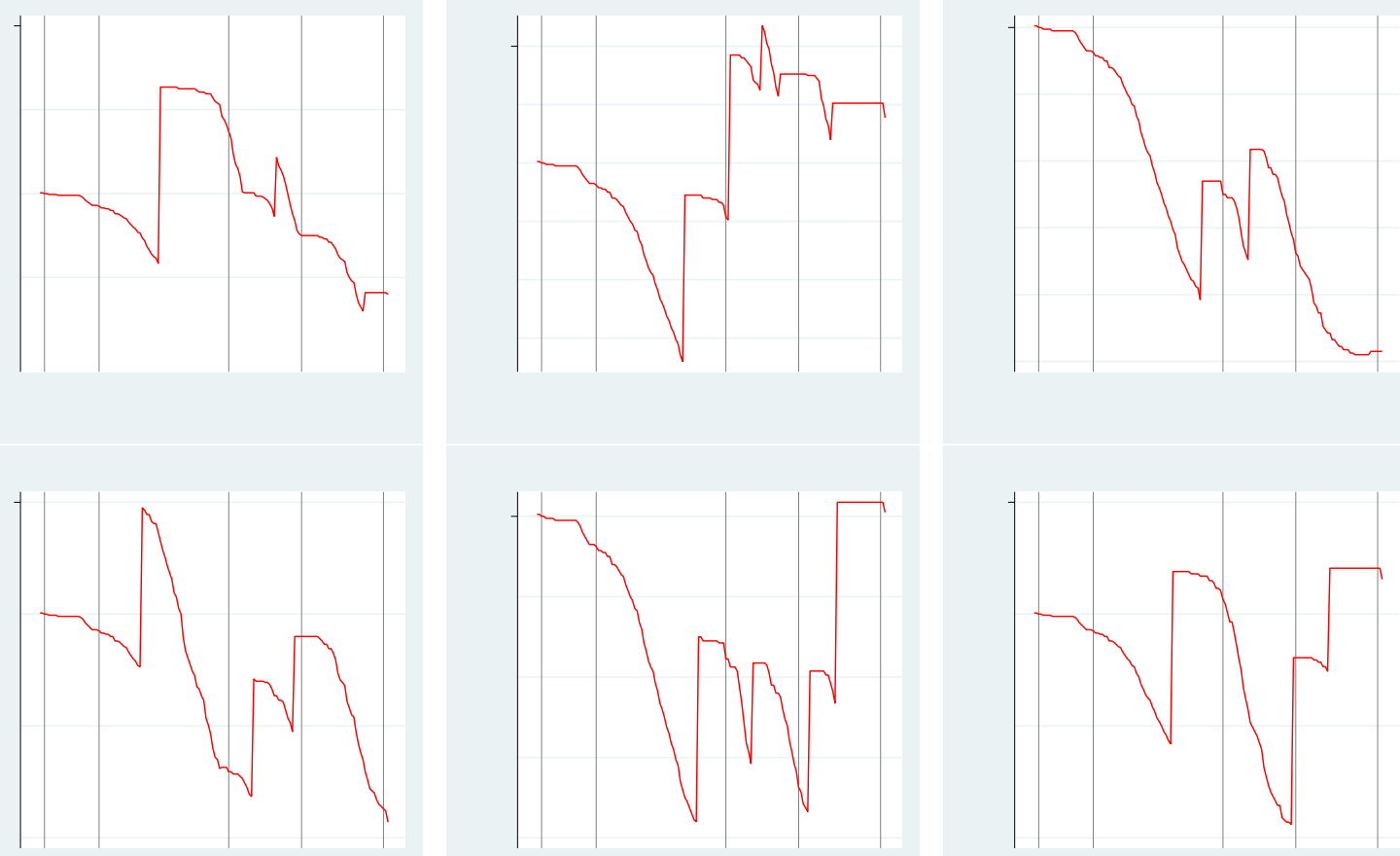

Sources: Authors' own calculation of telecom technology adoption ranking, based on Spectrum Launched Timeline from Telegeography.

Notes: The panels show the evolution of the indicator of the ranking of technology adoption. A higher value for the indicator for a given country indicates a higher ranking among all countries for a given year in telecom technology adoption. Time of the launch of $1 \mathrm{G}, 2 \mathrm{G}, 3 \mathrm{G}, 4 \mathrm{G}$, and $5 \mathrm{G}$ are marked as gray vertical lines for readers' reference. Details of the construction of this indicator are provided in Section II. 
Appendix Table 3. List of countries used in in Table 1 of the main text

\begin{tabular}{|c|c|c|c|}
\hline Afghanistan & Ecuador & Luxembourg & Slovak Republic \\
\hline Albania & Egypt, Arab Rep. & Madagascar & Slovenia \\
\hline Algeria & El Salvador & Malawi & South Africa \\
\hline Angola & Equatorial Guinea & Malaysia & Spain \\
\hline Argentina & Estonia & Maldives & Sri Lanka \\
\hline Armenia & Fiji & Mali & Sudan \\
\hline Australia & Finland & Mauritania & Suriname \\
\hline Austria & France & Mauritius & Sweden \\
\hline Azerbaijan & Gabon & Mexico & Switzerland \\
\hline Bahamas, The & Gambia, The & Moldova & Syrian Arab Republic \\
\hline Bahrain & Georgia & Mongolia & Tajikistan \\
\hline Bangladesh & Germany & Montenegro & Tanzania \\
\hline Barbados & Ghana & Morocco & Thailand \\
\hline Belarus & Greece & Mozambique & Timor-Leste \\
\hline Belgium & Grenada & Myanmar & Tonga \\
\hline Belize & Guatemala & Namibia & Trinidad and Tobago \\
\hline Bolivia & Guyana & Nepal & Tunisia \\
\hline Bosnia and Herzegovina & Honduras & Netherlands & Turkey \\
\hline Botswana & Hong Kong SAR, China & New Zealand & Tuvalu \\
\hline Brazil & Hungary & Nicaragua & Uganda \\
\hline Brunei Darussalam & Iceland & Niger & Ukraine \\
\hline Bulgaria & India & Nigeria & United Arab Emirates \\
\hline Burkina Faso & Indonesia & Norway & United Kingdom \\
\hline Cabo Verde & Iran, Islamic Rep. & Oman & United States \\
\hline Cambodia & Iraq & Pakistan & Uzbekistan \\
\hline Cameroon & Ireland & Panama & Vanuatu \\
\hline Canada & Italy & Papua New Guinea & Venezuela, RB \\
\hline Chile & Jamaica & Peru & Vietnam \\
\hline China & Japan & Philippines & Zimbabwe \\
\hline Colombia & Jordan & Poland & \\
\hline Comoros & Kazakhstan & Portugal & \\
\hline Congo, Dem. Rep. & Kenya & Qatar & \\
\hline Congo, Rep. & Kiribati & Romania & \\
\hline Costa Rica & Korea, Rep. & Russian Federation & \\
\hline Croatia & Kuwait & Rwanda & \\
\hline Cuba & Kyrgyz Republic & Samoa & \\
\hline Cyprus & Lao PDR & San Marino & \\
\hline Czech Republic & Latvia & Saudi Arabia & \\
\hline Côte d'Ivoire & Lesotho & Senegal & \\
\hline Denmark & Liberia & Serbia & \\
\hline Dominica & Liechtenstein & Seychelles & \\
\hline Dominican Republic & Lithuania & Singapore & \\
\hline
\end{tabular}


Appendix. Table 4. List of countries used in Table 2 in the main text

\begin{tabular}{|c|c|c|c|}
\hline Afghanistan & Côte d'Ivoire & Kuwait & Russian Federation \\
\hline Albania & Denmark & Kyrgyz Republic & Rwanda \\
\hline Algeria & Djibouti & Lao PDR & Samoa \\
\hline Andorra & Dominica & Latvia & San Marino \\
\hline Angola & Dominican Republic & Lebanon & Saudi Arabia \\
\hline Antigua and Barbuda & Ecuador & Lesotho & Senegal \\
\hline Argentina & Egypt, Arab Rep. & Liberia & Serbia \\
\hline Armenia & El Salvador & Libya & Seychelles \\
\hline Australia & Equatorial Guinea & Liechtenstein & Sierra Leone \\
\hline Austria & Eritrea & Lithuania & Singapore \\
\hline Azerbaijan & Estonia & Luxembourg & Slovak Republic \\
\hline Bahamas, The & Ethiopia & Madagascar & Slovenia \\
\hline Bahrain & Fiji & Malawi & Solomon Islands \\
\hline Bangladesh & Finland & Malaysia & Somalia \\
\hline Barbados & France & Maldives & South Africa \\
\hline Belarus & Gabon & Mali & Spain \\
\hline Belgium & Gambia, The & Mauritania & Sri Lanka \\
\hline Belize & Georgia & Mauritius & Sudan \\
\hline Benin & Germany & Mexico & Suriname \\
\hline Bhutan & Ghana & Moldova & Sweden \\
\hline Bolivia & Greece & Monaco & Switzerland \\
\hline Bosnia and Herzegovina & Grenada & Mongolia & Syrian Arab Republic \\
\hline Botswana & Guatemala & Montenegro & Tajikistan \\
\hline Brazil & Guinea & Morocco & Tanzania \\
\hline Brunei Darussalam & Guinea-Bissau & Mozambique & Thailand \\
\hline Bulgaria & Guyana & Myanmar & Timor-Leste \\
\hline Burkina Faso & Haiti & Namibia & Togo \\
\hline Burundi & Honduras & Nepal & Tonga \\
\hline Cabo Verde & Hong Kong SAR, China & Netherlands & Trinidad and Tobago \\
\hline Cambodia & Hungary & New Zealand & Tunisia \\
\hline Cameroon & Iceland & Nicaragua & Turkey \\
\hline Canada & India & Niger & Turkmenistan \\
\hline Central African Republic & Indonesia & Nigeria & Tuvalu \\
\hline Chad & Iran, Islamic Rep. & Norway & Uganda \\
\hline Chile & Iraq & Oman & Ukraine \\
\hline China & Ireland & Pakistan & United Arab Emirates \\
\hline Colombia & Italy & Panama & United Kingdom \\
\hline Comoros & Jamaica & Papua New Guinea & United States \\
\hline Congo, Dem. Rep. & Japan & Paraguay & Uruguay \\
\hline Congo, Rep. & Jordan & Peru & Uzbekistan \\
\hline Costa Rica & Kazakhstan & Philippines & Vanuatu \\
\hline Croatia & Kenya & Poland & Venezuela, RB \\
\hline Cuba & Kiribati & Portugal & Vietnam \\
\hline Cyprus & Korea, Dem. People's Rep. & Qatar & Yemen, Rep. \\
\hline Czech Republic & Korea, Rep. & Romania & Zambia \\
\hline
\end{tabular}


Appendix. Table 5. First Stage of Instrumental Variable Regressions linking Stock Returns and Technology Adoption

\begin{tabular}{lcccc}
\hline Dep. Variable & \multicolumn{4}{c}{ Technology adoption window } \\
\cline { 2 - 5 } & $(1)$ & $(2)$ & $(3)$ & $(4)$ \\
\hline Liberalization (t-1) & $0.186^{* * *}$ & $0.187^{* * * *}$ & $0.187^{* * *}$ & $0.205^{* * *}$ \\
& $(0.0426)$ & $(0.0427)$ & $(0.0427)$ & $(0.0343)$ \\
Regulatory Score (t-1) & $-0.237^{* * *}$ & $-0.234^{* * *}$ & $-0.234^{* * *}$ & $-0.356^{* * *}$ \\
& $(0.0504)$ & $(0.0505)$ & $(0.0505)$ & $(0.0726)$ \\
Liberalization (t-1) x Regulatory Score (t-1) & -0.0772 & -0.0755 & -0.0756 & -0.0759 \\
& $(0.0514)$ & $(0.0515)$ & $(0.0516)$ & $(0.0563)$ \\
World Stock Returns & & & 0.0666 & 0.140 \\
& & & $(0.0841)$ & $(0.102)$ \\
Country Fixed Effects & Yes & Yes & Yes & Yes \\
Lag Dependent & No & Yes & Yes & Yes \\
Macro Fundamentals & No & No & No & Yes \\
& & & & \\
Observations & 8700 & 8700 & 8700 & 6300 \\
F-stat (Weak Identification Test) & 44.89 & 44.63 & 44.53 & 48.63 \\
\hline
\end{tabular}

Notes: This table presents the first stage of the IV regression that was discussed in Table 4, and F-stat from Weak Identification Test is displayed in the last row of the table. The dependent variable is the technology adoption window. Liberalization is a dummy variable, measured as 0 before the year of liberalization and 1 on the year of liberalization and thereafter. Regulatory Score is an indicator between 0 and 1 , where 1 indicates highest score in ICT regulatory authority. Robust standard errors are given in parentheses. ${ }^{*} \mathrm{p}<0.1,{ }^{* *} \mathrm{p}<0.05,{ }^{* * *} \mathrm{p}<0.01$. 
Appendix Table 6. Technology Adoption, Foreign Direct Investment and Regulatory Independence

\begin{tabular}{lcccc}
\hline Dep. Variable & \multicolumn{4}{c}{ Technology adoption score } \\
\cline { 2 - 5 } & $(1)$ & $(2)$ & $(3)$ & $(4)$ \\
\hline Foreign Investment (t-1) & $-1.034^{* * *}$ & $-0.963^{* * *}$ & $-0.757^{* * *}$ & $-0.613^{* * *}$ \\
& $(0.320)$ & $(0.344)$ & $(0.272)$ & $(0.217)$ \\
Regulatory Score (t-1) & 6.563 & 15.97 & 17.67 & 13.86 \\
& $(8.104)$ & $(11.32)$ & $(11.37)$ & $(10.21)$ \\
Foreign Investment (t-1) x Regulatory Score (t-1) & $1.054^{* * *}$ & $0.983^{* * *}$ & $0.824^{* * *}$ & $0.701^{* * *}$ \\
& $(0.344)$ & $(0.372)$ & $(0.292)$ & $(0.232)$ \\
Population (log) & No & No & Yes & Yes \\
GDP per capita (log) & No & No & Yes & Yes \\
Fixed effects & & & & \\
Country & Yes & Yes & Yes & Yes \\
Year & No & Yes & Yes & Yes \\
Technology Generation & No & No & No & Yes \\
Observations & & & & \\
R-squared & 928 & 928 & 924 & 924 \\
\hline
\end{tabular}

Notes: This table presents coefficients from OLS regressions, based on annual data from 2005 to 2017. Dependent variable is technology adoption score, which is the opposite of technology adoption ranking. Foreign investment is the ratio of capex FDI in communications industry from fDi Intelligence, to annual investment in telecommunication services from ITU, during the same year. Regulatory Score is an indicator between 0 and 1, where 1 indicates highest score in ICT regulatory authority. Regression in column (1) controls for country fixed effects; regressions in column (2) to (4) control for both country and year fixed effects; while regression in column (4) controls for, in addition, the fixed effect of the generation of technology that was adopted. Robust standard errors in parentheses. *, ** and *** denote significance at $10 \%, 5 \%$, and $1 \%$, respectively. 
Appendix. Table 7. Stock Returns and Technology Adoption controlling for IT index

\begin{tabular}{lcccc}
\hline Dep. Variable & \multicolumn{4}{c}{ Stock Returns } \\
\cline { 2 - 5 } & $(1)$ & $(2)$ & $(3)$ & $(4)$ \\
\hline Technology Adoption Window & $0.00401^{* *}$ & $0.00377^{* *}$ & $0.00421^{* * *}$ & $0.00426^{* *}$ \\
& $(0.00178)$ & $(0.00176)$ & $(0.00158)$ & $(0.00171)$ \\
IT Stock Returns & $0.403^{* * *}$ & $0.389^{* * *}$ & $0.253^{* * *}$ & $0.209^{* * *}$ \\
& $(0.0204)$ & $(0.0204)$ & $(0.0197)$ & $(0.0219)$ \\
World Stock Returns & & & $0.681^{* * *}$ & $0.711^{* * *}$ \\
& & & $(0.0308)$ & $(0.0350)$ \\
Country Fixed Effects & Yes & Yes & Yes & Yes \\
Lag Dependent & No & Yes & Yes & Yes \\
Macro Fundamentals & No & No & No & Yes \\
& & & & \\
Observations & 5800 & 5791 & 5791 & 4040 \\
R-squared & 0.434 & 0.443 & 0.576 & 0.605
\end{tabular}

Notes: This table presents coefficients from OLS regressions that follow corresponding regressions in Table 3, after controlled for IT Stock Returns. Dependent variable is country's stock returns, and IT Stock Returns is the country's stock returns in IT sector, calculated from MSCI IT Index. Technology adoption window is a dummy variable that takes the value of one for the event window of the adoption of a new generation in telecom technology. The event window begins seven months prior to the adoption month and ends in the adoption month. A lagged dependent variable is introduced in column (2) to (4) to reduce the occurrence of autocorrelation. World stock returns is introduced as benchmark control variables in column (3) to (4), based on monthly average of daily return of MSCI Total Return Index of World. Macroeconomic fundamentals are introduced in column (4), that includes monthly growth rate of exchange rate, consumer price index, and political risk rating, respectively, in period $t-1, t$, and $t+1$. All regressions control for country fixed effects. Robust standard errors in parentheses. *, ** and *** denote significance at $10 \%, 5 \%$, and $1 \%$, respectively. 
Appendix. Table 8. Instrumental Variable Regression: Stock Returns and Technology Adoption controlling for IT Index

\begin{tabular}{lcccc}
\hline Dep. Variable & \multicolumn{4}{c}{ Stock Returns } \\
\cline { 2 - 5 } & $(1)$ & $(2)$ & $(3)$ & $(4)$ \\
\hline Technology Adoption Window & $0.0427^{* * *}$ & $0.0322^{* *}$ & $0.0214^{*}$ & $0.0351^{* * *}$ \\
& $(0.0153)$ & $(0.0148)$ & $(0.0112)$ & $(0.0101)$ \\
IT Stock Returns & $0.504^{* * *}$ & $0.481^{* * *}$ & $0.234^{* * *}$ & $0.209^{* * *}$ \\
& $(0.00870)$ & $(0.00858)$ & $(0.00832)$ & $(0.00926)$ \\
World Stock Returns & & & $0.831^{* * *}$ & $0.842^{* * *}$ \\
& & & $(0.0173)$ & $(0.0194)$ \\
Country Fixed Effects & Yes & Yes & Yes & Yes \\
Lag Dependent & No & Yes & Yes & Yes \\
Macro Fundamentals & No & No & No & Yes \\
& & & & \\
Observations & 3499 & 3499 & 3499 & 2653 \\
R-squared & 0.466 & 0.510 & 0.717 & 0.721 \\
\hline
\end{tabular}

Notes: This table presents coefficients from instrumental-variables OLS regressions, where country's IT stock return is controlled for, and technology adoption window is instrumented, with excluded instruments being one-period lagged liberalization, one-period lagged regulatory score, and their interactions. Country fixed effects and constants are included each column. A lagged dependent variable is introduced in column (2) to (4) to reduce the occurrence of autocorrelation. World stock returns is introduced as benchmark control variables in column (3) to (4), based on monthly average of daily return of MSCI Total Return Index of World. Macroeconomic fundamentals are introduced in column (4), that includes monthly growth rate of exchange rate, consumer price index, and political risk rating, respectively, in period $t-1, t$, and $t+1$. Robust standard errors in parentheses. *,** and *** denote significance at $10 \%, 5 \%$, and $1 \%$, respectively. 
Appendix. Table 9. First stage of Regression using IT stock index

\begin{tabular}{lcccc}
\hline Dep. Variable & \multicolumn{4}{c}{ Technology adoption window } \\
\cline { 2 - 5 } & $(1)$ & $(2)$ & $(3)$ & $(4)$ \\
\hline Liberalization (t-1) & $0.468^{* * *}$ & $0.468^{* * *}$ & $0.468^{* * *}$ & \\
& $(0.108)$ & $(0.108)$ & $(0.108)$ & \\
Regulatory Score (t-1) & 0.119 & 0.120 & 0.120 & $-0.496^{* * *}$ \\
& $(0.179)$ & $(0.179)$ & $(0.179)$ & $(0.0603)$ \\
Liberalization (t-1) x Regulatory Score (t-1) & $-0.467^{* *}$ & $-0.466^{* *}$ & $-0.466^{* *}$ & \\
& $(0.186)$ & $(0.186)$ & $(0.186)$ & \\
IT Stock Returns & -0.00630 & -0.0143 & -0.00677 & 0.0387 \\
& $(0.0719)$ & $(0.0741)$ & $(0.0944)$ & $(0.111)$ \\
World Stock Returns & & & -0.0253 & -0.104 \\
& & & $(0.196)$ & $(0.234)$ \\
Country Fixed Effects & Yes & Yes & Yes & Yes \\
Lag Dependent & No & Yes & Yes & Yes \\
Macro Fundamentals & No & No & No & Yes \\
& & & & \\
Observations & 3499 & 3499 & 3499 & 2653 \\
F-stat (Weak Identification Test) & 20.8 & 20.56 & 20.56 & 67.72 \\
\hline
\end{tabular}

Notes: This table presents the first stage of the IV regression that was discussed in Table 8, and F-stat from Weak Identification Test is displayed in the last row of the table. The dependent variable is the technology adoption window. Liberalization is a dummy variable, measured as 0 before the year of liberalization and 1 on the year of liberalization and thereafter. Regulatory Score is an indicator between 0 and 1 , where 1 indicates highest score in ICT regulatory authority. Robust standard errors are given in parentheses. ${ }^{*} \mathrm{p}<0.1,{ }^{* *} \mathrm{p}<0.05, * * * \mathrm{p}<0.01$. 
Appendix. Table 10. Stock Returns Sub-indexes and Technology Adoption

\begin{tabular}{|c|c|c|c|c|c|c|c|}
\hline \multirow{2}{*}{$\begin{array}{l}\text { Dep. Variable: } \\
\text { Sector: }\end{array}$} & \multicolumn{7}{|c|}{ Stock Returns } \\
\hline & $\begin{array}{l}\text { IT } \\
(1) \\
\end{array}$ & $\begin{array}{c}\text { Energy } \\
(2) \\
\end{array}$ & $\begin{array}{c}\text { Financials } \\
(3) \\
\end{array}$ & $\begin{array}{c}\text { Materials } \\
(4) \\
\end{array}$ & $\begin{array}{c}\text { Consumer Staples } \\
(5) \\
\end{array}$ & $\begin{array}{c}\text { Health Care } \\
(6) \\
\end{array}$ & $\begin{array}{c}\text { Industrials } \\
(7)\end{array}$ \\
\hline Technology Adoption Window & $\begin{array}{c}0.00476 \\
(0.00295)\end{array}$ & $\begin{array}{l}-0.00110 \\
(0.00234)\end{array}$ & $\begin{array}{c}0.00437 * * * \\
(0.00163)\end{array}$ & $\begin{array}{c}0.00216 \\
(0.00161)\end{array}$ & $\begin{array}{c}0.00180 \\
(0.00163)\end{array}$ & $\begin{array}{c}0.00928 * * * \\
(0.00273)\end{array}$ & $\begin{array}{c}0.00446 * * * \\
(0.00170)\end{array}$ \\
\hline World Stock Returns ${ }^{+}$ & $\begin{array}{c}0.930 * * * \\
(0.0237)\end{array}$ & $\begin{array}{c}0.944 * * * \\
(0.0205)\end{array}$ & $\begin{array}{l}0.861 * * * \\
(0.0174)\end{array}$ & $\begin{array}{c}0.923 * * * \\
(0.0164)\end{array}$ & $\begin{array}{c}0.874 * * * \\
(0.0275)\end{array}$ & $\begin{array}{l}0.765 * * * \\
(0.0401)\end{array}$ & $\begin{array}{l}0.965 * * * \\
(0.0190)\end{array}$ \\
\hline Country Fixed Effects & Yes & Yes & Yes & Yes & Yes & Yes & Yes \\
\hline Lag Dependent & Yes & Yes & Yes & Yes & Yes & Yes & Yes \\
\hline Observations & 6166 & 7174 & 13429 & 11775 & 9980 & 6005 & 10085 \\
\hline R-squared & 0.385 & 0.331 & 0.335 & 0.400 & 0.218 & 0.150 & 0.380 \\
\hline
\end{tabular}

${ }^{+}$World Stock Returns in each column represents corresponding world index for each sector.

Notes: This table presents coefficients from OLS regressions on stock sub-indices, including IT, Energy, Financials, Materials, Consumer Staples, Health Care, and Industrials. World stock returns in each column refers to corresponding world sub-index for each sector. Country and year fixed effects are included in all columns. Robust standard errors in parentheses. $*, * *$ and $* * *$ denote significance at $10 \%, 5 \%$, and $1 \%$, respectively. 
Appendix. Table 11. IT Stock Returns and Technology Adoption

\begin{tabular}{lcccc}
\hline Dep. Variable & \multicolumn{4}{c}{ IT Stock Returns } \\
\cline { 2 - 5 } & $(1)$ & $(2)$ & $(3)$ & $(4)$ \\
\hline Technology Adoption Window & -0.00133 & -0.00104 & 0.00476 & $0.00781^{* *}$ \\
& $(0.00395)$ & $(0.00376)$ & $(0.00295)$ & $(0.00348)$ \\
IT World Stock Returns & & & $0.930^{* * *}$ & $0.963^{* * *}$ \\
& & & $(0.0237)$ & $(0.0274)$ \\
Country Fixed Effects & Yes & Yes & Yes & Yes \\
Lag Dependent & No & Yes & Yes & Yes \\
Macro Fundamentals & No & No & No & Yes \\
& & & & 4235 \\
Observations & 6203 & 6166 & 6166 & 0.423 \\
R-squared & 0.0143 & 0.109 & 0.385 & \\
\hline
\end{tabular}

Notes: This table presents coefficients from OLS regressions of stock returns in MSCI IT sub-index. Technology adoption window is a dummy variable for the event window of the adoption of a new generation in telecom technology. The event window begins seven months prior to the adoption month and ends in the adoption month. Constants and country fixed effects are included in all columns. A lagged dependent variable is introduced in column (2) to (4) to reduce the occurrence of autocorrelation. World stock returns is introduced as benchmark control variables in column (3) to (4). Macroeconomic fundamentals are introduced in column (4), that includes monthly growth rate of exchange rate, consumer price index, and political risk rating, respectively, in period $t-1, t$, and $t+1$. All regressions control for country fixed effects. Robust standard errors in parentheses. $*, * *$ and $* * *$ denote significance at $10 \%, 5 \%$, and $1 \%$, respectively. 
Appendix. Table 12. Energy Stock Returns and Technology Adoption

\begin{tabular}{lcccc}
\hline Dep. Variable & \multicolumn{4}{c}{ Energy Stock Returns } \\
\cline { 2 - 5 } & $(1)$ & $(2)$ & $(3)$ & $(4)$ \\
\hline Technology Adoption Window & -0.00315 & -0.00253 & -0.00110 & -0.000578 \\
& $(0.00295)$ & $(0.00289)$ & $(0.00234)$ & $(0.00278)$ \\
Energy World Stock Returns & & & $0.944^{* * *}$ & $0.956^{* * *}$ \\
& & & $(0.0205)$ & $(0.0221)$ \\
Country Fixed Effects & Yes & Yes & Yes & Yes \\
Lag Dependent & No & Yes & Yes & Yes \\
Macro Fundamentals & No & No & No & Yes \\
& & & & \\
Observations & 7209 & 7174 & 7174 & 5233 \\
R-squared & 0.00258 & 0.0596 & 0.331 & 0.398 \\
\hline
\end{tabular}

Notes: This table presents coefficients from OLS regressions of stock returns in $\mathrm{MSCl}$ Energy sub-index. Technology adoption window is a dummy variable for the event window of the adoption of a new generation in telecom technology. The event window begins seven months prior to the adoption month and ends in the adoption month. Constants and country fixed effects are included in all columns. A lagged dependent variable is introduced in column (2) to (4) to reduce the occurrence of autocorrelation. World stock returns is introduced as benchmark control variables in column (3) to (4). Macroeconomic fundamentals are introduced in column (4), that includes monthly growth rate of exchange rate, consumer price index, and political risk rating, respectively, in period $t-1, t$, and $t+1$. All regressions control for country fixed effects. Robust standard errors in parentheses. ${ }^{*},{ }^{* *}$ and ${ }^{* * *}$ denote significance at $10 \%, 5 \%$, and $1 \%$, respectively. 
Appendix. Table 13. Financials Stock Returns and Technology Adoption

\begin{tabular}{lcccc}
\hline Dep. Variable & \multicolumn{4}{c}{ Financials Stock Returns } \\
\cline { 2 - 5 } & $(1)$ & $(2)$ & $(3)$ & $(4)$ \\
\hline Technology Adoption Window & $0.00809^{* * *}$ & $0.00537^{* * *}$ & $0.00437^{* * *}$ & $0.00356^{*}$ \\
& $(0.00207)$ & $(0.00197)$ & $(0.00163)$ & $(0.00182)$ \\
Financials World Stock Returns & & & $0.861^{* * *}$ & $0.905^{* * *}$ \\
& & & $(0.0174)$ & $(0.0201)$ \\
Country Fixed Effects & Yes & Yes & Yes & Yes \\
Lag Dependent & No & Yes & Yes & Yes \\
Macro Fundamentals & No & No & No & Yes \\
& & & & \\
Observations & 13483 & 13429 & 13429 & 8821 \\
R-squared & 0.00857 & 0.105 & 0.335 & 0.440 \\
\hline
\end{tabular}

Notes: This table presents coefficients from OLS regressions of stock returns in MSCl Financials sub-index. Technology adoption window is a dummy variable for the event window of the adoption of a new generation in telecom technology. The event window begins seven months prior to the adoption month and ends in the adoption month. Constants and country fixed effects are included in all columns. A lagged dependent variable is introduced in column (2) to (4) to reduce the occurrence of autocorrelation. World stock returns is introduced as benchmark control variables in column (3) to (4). Macroeconomic fundamentals are introduced in column (4), that includes monthly growth rate of exchange rate, consumer price index, and political risk rating, respectively, in period $t-1, t$, and $t+1$. All regressions control for country fixed effects. Robust standard errors in parentheses. ${ }^{*}, * *$ and ${ }^{* * *}$ denote significance at $10 \%, 5 \%$, and $1 \%$, respectively. 
Appendix. Table 14. Materials Stock Returns and Technology Adoption

\begin{tabular}{lcccc}
\hline Dep. Variable & \multicolumn{4}{c}{ Materials Stock Returns } \\
\cline { 2 - 5 } & $(1)$ & $(2)$ & $(3)$ & $(4)$ \\
\hline Technology Adoption Window & $0.00528^{* *}$ & $0.00373^{*}$ & 0.00216 & $0.00316^{*}$ \\
& $(0.00216)$ & $(0.00208)$ & $(0.00161)$ & $(0.00181)$ \\
Materials World Stock Returns & & & $0.923^{* * *}$ & $0.907^{* * *}$ \\
& & & $(0.0164)$ & $(0.0201)$ \\
Country Fixed Effects & Yes & Yes & Yes & Yes \\
Lag Dependent & No & Yes & Yes & Yes \\
Macro Fundamentals & No & No & No & Yes \\
& & & & \\
Observations & 11832 & 11775 & 11775 & 7999 \\
R-squared & 0.00264 & 0.0984 & 0.400 & 0.453 \\
\hline Nos: This
\end{tabular}

Notes: This table presents coefficients from OLS regressions of stock returns in MSCI Materials sub-index. Technology adoption window is a dummy variable for the event window of the adoption of a new generation in telecom technology. The event window begins seven months prior to the adoption month and ends in the adoption month. Constants and country fixed effects are included in all columns. A lagged dependent variable is introduced in column (2) to (4) to reduce the occurrence of autocorrelation. World stock returns is introduced as benchmark control variables in column (3) to (4). Macroeconomic fundamentals are introduced in column (4), that includes monthly growth rate of exchange rate, consumer price index, and political risk rating, respectively, in period $t-1, t$, and $t+1$. All regressions control for country fixed effects. Robust standard errors in parentheses. $*, * *$ and $* * *$ denote significance at $10 \%, 5 \%$, and $1 \%$, respectively. 
Appendix. Table 15. Consumer Staples Stock Returns and Technology Adoption

\begin{tabular}{lcccc}
\hline Dep. Variable & \multicolumn{4}{c}{ Consumer Staples Stock Returns } \\
\cline { 2 - 5 } & $(1)$ & $(2)$ & $(3)$ & $(4)$ \\
\hline Technology Adoption Window & $0.00395^{* *}$ & $0.00311^{*}$ & 0.00180 & 0.00121 \\
& $(0.00187)$ & $(0.00180)$ & $(0.00163)$ & $(0.00180)$ \\
Consumer Staples World Stock Returns & & & $0.874^{* * *}$ & $0.920^{* * *}$ \\
& & & $(0.0275)$ & $(0.0296)$ \\
Country Fixed Effects & Yes & Yes & Yes & Yes \\
Lag Dependent & No & Yes & Yes & Yes \\
Macro Fundamentals & No & No & No & Yes \\
& & & & \\
Observations & 10034 & 9980 & 9980 & 7045 \\
R-squared & 0.00269 & 0.0756 & 0.218 & 0.302 \\
\hline
\end{tabular}

Notes: This table presents coefficients from OLS regressions of stock returns in MSCl Consumer Staples sub-index. Technology adoption window is a dummy variable for the event window of the adoption of a new generation in telecom technology. The event window begins seven months prior to the adoption month and ends in the adoption month. Constants and country fixed effects are included in all columns. A lagged dependent variable is introduced in column (2) to (4) to reduce the occurrence of autocorrelation. World stock returns is introduced as benchmark control variables in column (3) to (4). Macroeconomic fundamentals are introduced in column (4), that includes monthly growth rate of exchange rate, consumer price index, and political risk rating, respectively, in period $t-1, t$, and $t+1$. All regressions control for country fixed effects. Robust standard errors in parentheses. ${ }^{*}, * *$ and ${ }^{* * *}$ denote significance at $10 \%, 5 \%$, and $1 \%$, respectively. 
Appendix. Table 16. Health Care Stock Returns and Technology Adoption

\begin{tabular}{lcccc}
\hline Dep. Variable & \multicolumn{4}{c}{ Health Care Stock Returns } \\
\cline { 2 - 5 } & $(1)$ & $(2)$ & $(3)$ & $(4)$ \\
\hline Technology Adoption Window & $0.0105^{* * *}$ & $0.00831^{* * *}$ & $0.00928^{* * *}$ & $0.0137^{* * *}$ \\
& $(0.00299)$ & $(0.00284)$ & $(0.00273)$ & $(0.00323)$ \\
Health Care World Stock Returns & & & $0.765^{* * *}$ & $0.880^{* * *}$ \\
& & & $(0.0401)$ & $(0.0434)$ \\
Country Fixed Effects & Yes & Yes & Yes & Yes \\
Lag Dependent & No & Yes & Yes & Yes \\
Macro Fundamentals & No & No & No & Yes \\
& & & & \\
Observations & 6033 & 6005 & 6005 & 4337 \\
R-squared & 0.00445 & 0.0681 & 0.150 & 0.188
\end{tabular}

Notes: This table presents coefficients from OLS regressions of stock returns in MSCI Health Care sub-index. Technology adoption window is a dummy variable for the event window of the adoption of a new generation in telecom technology. The event window begins seven months prior to the adoption month and ends in the adoption month. Constants and country fixed effects are included in all columns. A lagged dependent variable is introduced in column (2) to (4) to reduce the occurrence of autocorrelation. World stock returns is introduced as benchmark control variables in column (3) to (4). Macroeconomic fundamentals are introduced in column (4), that includes monthly growth rate of exchange rate, consumer price index, and political risk rating, respectively, in period $t-1, t$, and $t+1$. All regressions control for country fixed effects. Robust standard errors in parentheses. $*, * *$ and $* * *$ denote significance at $10 \%, 5 \%$, and $1 \%$, respectively. 
Appendix. Table 17. Industrial Stock Returns and Technology Adoption

\begin{tabular}{lcccc}
\hline Dep. Variable & \multicolumn{4}{c}{ Industrials Stock Returns } \\
\cline { 2 - 5 } & $0.00641^{* * *}$ & $0.00458^{* *}$ & $0.00446^{* * *}$ & 0.00295 \\
\hline Technology Adoption Window & $(0.00217)$ & $(0.00206)$ & $(0.00170)$ & $(0.00185)$ \\
& & & $0.965^{* * *}$ & $0.971^{* * *}$ \\
Industrials World Stock Returns & & & $(0.0190)$ & $(0.0206)$ \\
& Yes & Yes & Yes & Yes \\
Country Fixed Effects & No & Yes & Yes & Yes \\
Lag Dependent & No & No & No & Yes \\
Macro Fundamentals & & & & \\
& 10133 & 10085 & 10085 & 6917 \\
Observations & 0.00437 & 0.0968 & 0.380 & 0.464 \\
R-squared & & & & \\
\hline
\end{tabular}

Notes: This table presents coefficients from OLS regressions of stock returns in MSCI Industrial sub-index. Technology adoption window is a dummy variable for the event window of the adoption of a new generation in telecom technology. The event window begins seven months prior to the adoption month and ends in the adoption month. Constants and country fixed effects are included in all columns. A lagged dependent variable is introduced in column (2) to (4) to reduce the occurrence of autocorrelation. World stock returns is introduced as benchmark control variables in column (3) to (4). Macroeconomic fundamentals are introduced in column (4), that includes monthly growth rate of exchange rate, consumer price index, and political risk rating, respectively, in period $t-1, t$, and $t+1$. All regressions control for country fixed effects. Robust standard errors in parentheses. $*, * *$ and $* * *$ denote significance at $10 \%, 5 \%$, and $1 \%$, respectively. 


\section{Supplementary Appendix. From 1G to 5G Technology}

5G communication promises to carry transformational changes to the mobile industry, with substantial performance advances. These include a 20x improvement in the peak data rate, 10 times less latency and 2 times more spectral efficiency (Pasquali, 2019), as well as innovative business models. The topic of technology adoption, including the optimal enabling environment to accelerate the diffusion of $5 \mathrm{G}$, is now core to the global policy debate. Policy-makers in high income and emerging economies debate the "race to $5 G$ ", raise security and strategic concerns about specific network manufacturers, advocate a re-hauling of policies and regulations. Many advocate the need to enhance government coordination over a disruptive, complex network. National security prerogatives are prominently invoked.

$5 \mathrm{G}$ is the newest technology but the debate is a century old. Ronald Coase, in his seminal work on the birth of the Federal Communications Commission, indicates that "The history of regulation in the broadcasting industry demonstrates the crucial importance of events in the early days of a new development in determining long-run governmental policy. It also suggests that lawyers and economists should not be overwhelmed by the emergence of new technologies as to change the existing legal and economic system without first making quite certain that this is required." (Coase, 1959). Coase indicates that before the creation of the Federal Communications Commission, several bills attempted to create a monopoly on electronic communications, alleging national security and government coordination reasons. Coase indicates that "A bill was even introduced to create a Post Office monopoly on electrical communications. In 1917 and 1918, bills were introduced which would have given control of the radio industry to the Department of the Navy." Coase indicate that the Secretary of the Department of the Navy advocated to give to the Navy the "exclusive ownership, of all wireless communications for commercial purposes". He also mentioned that the rationale indicated for granting this exclusive control to the Navy, which had developed significant operational expertise during World War I, was to promote government coordination, and avoid "interference". Coase suggests that the grounds of coordination and interference were also mentioned by Secretary of Commerce Hoover to remove the license granted to a private monopoly telegraph company. Hoover decision was reverted by Court, which determined that the government had "no control on the number of stations that could be established". Years of debate ensued, with occasional lawsuits challenging the decisions of the Department of Commerce, and leading to the act that in 1927 brought into existence the Federal Communications Commission. The FCC was tasked to "assign wave lengths, determine the power and location of the transmitters, determine the type of apparatus used, and make regulations to prevent interference". The FCC had a discretionary power to issue licenses. Coase observes that "The is nothing in the technology of the broadcasting industry that prevents the use of [marketbased mechanisms]", recognizing that interference raises potential transaction costs, creating a rationale for light touch regulation. (Coase, 1959)

The mobile telecom technology possesses the three major characteristics of a general-purpose technology as already detailed in Bresnahan and Trajtenberg (1996). It is pervasive since most sectors use mobile telecom technology to some extent; it gets improved over time, with five successive generations of the technology having been developed; it creates innovation spawning with many new services becoming possible. Because they affect the whole economy, understanding the process of adoption and diffusion of general-purpose technologies has been a cornerstone of studies focusing on cross-country differences in growth and total factor productivity patterns. Comin and Hobijn (2009a) have assembled the Cross-Country Historical Adoption Database (CHAT database) to document adoption of major technologies across the world over two centuries. In Comin and Hobijn (2010), they propose an indirect measure of country-specific lags in technology adoption, based on the curvature of productivity. Interestingly, our focus on the mobile telecom sector allows us to have a direct measure of technology adoption lags since spectrum award and 
service launch timelines are documented in the Telegeography database. In Comin and Hobijn (2009b), they study the effect of institutional variables that affect the cost of lobbying and erecting barriers to entry on the speed of technology diffusion. They find that the effect is significantly larger when the technology has a close predecessor. They interpret this result as showing the importance of lobbying by incumbents in order to slow down technology diffusion. Our narrow focus on the successive generations of mobile technology allows us to scrutinize the country-specific market structures in that industry and how it affects the incentives to adopt the latest technology. Cervellati et al. (2018) use the CHAT database to analyse the links between democratization, openness to trade and incentives for technology adoption. We share with the two latter references the idea that technology adoption is not only a decision taken by individual firms. In the mobile telecom sector, governments, whether benevolent or captured by specific interests, play a key role.

Accompanying the movement of telecom sector reforms across the world, the literature on the industrial organization and competitive dynamics of telecom has broadly focused on the following issue: following liberalization, will sector-specific regulation soon give way to competition policy? (see for instance Laffont et al., 1997). Therefore, this literature has taken a normative or positive approach to document the interplay among liberalization, privatization and regulation of the telecom industry.

As a first consideration, there is ample evidence in the literature that the strength in the regulatory regime influence investment decisions. Levy and Spiller (1994) stress on the importance of regulatory credibility as a credible commitment which is necessary to achieve long term investment in network industries. This holds both in advanced economies and in emerging markets, where credible regulation has a chance to emerge in "unpropitious" environments. The role of an independent sector regulator to reduce regulatory uncertainty, coupled with incentive regulation, is found to have had an impact on investment in network industries, especially when combined with reduction of entry barriers to increase market contestability (Balazs, 2009). Other researches found convincing evidence that privatization combined with an independent regulator enhances telecom performance measures, while privatization alone would not bring positive results in terms of performance and access (Wallsten, 2003). Regulatory capture risk has been identified throughout the economic literature as a major risk of reform, both in advanced and emerging governance frameworks. By contrast, the simple issuance of competitive licenses in countries with weak governance framework, while it had an important impact on market performance, can also result in the sector to be dominated by cronyism. According to Sutherland, 2012, in Africa new licenses were often assigned to "cronies and to bribe payers. License conditions could be varied by bribes - buying lower levels of competition or exclusivity. [...]. Often the price was raised and with it the bribes by sweetening the terms (e.g., adding a wireless licence)".

Hence, the need in the literature to assess sector reform in terms of contestability, effective competition, as well as quality and independence of regulatory agencies.

Contestability and the ability to enabling markets to have been a core feature of the diffusion of different generations of mobile technology. In an early study on mobile telephony adoption in Eastern Europe, simultaneous entry of different operations was found more effective than sequential entry in accelerating diffusion speed (Gruber, 2001). Reflecting on the introduction of mobile competition through 2G GSM technology in Morocco, Wellenius and Rossotto (2000) stressed on the importance of creating and strengthening an independent regulator, while awarding a competitive license. Islam and Meade (2012) found that market contestability and integration in the global economy were key factors to accelerate the diffusion of $3 \mathrm{G}$ services across countries. Using a hedonic price model to study the French market, Nicolle and others (2018), found that the "reduction in quality-adjusted prices in the last years was largely caused by competition between operators for a new technology (4G). The entry of a fourth low-cost operator also 
induced a quality-adjusted price decrease, although at a lower scale.". The move to $3 \mathrm{G}$ to $4 \mathrm{G}$, in other words, allowed not only for a technology enhancement of the wireless infrastructure and services, but also allowed benevolent regulators to intervene on the market structure and introduce a new operator. Nicolle et al. (2018) also note that in the $2 \mathrm{G}$ and $3 \mathrm{G}$ markets, still dominated by voice-centered business models, mobile prices drove antitrust investigations including collusion and merger cases, such as in a high-profile collusion case in mobile telephony, detected and prosecuted in France in 2005. The postmerger prices of mobile services were the main concern of competition authorities in assessing mobile mergers in Austria in 2006 (T-Mobile acquiring tele.ring), the Netherlands in 2007 (merger of T-Mobile and Orange), in the United Kingdom in 2010 (T-Mobile and Orange), and in Germany in 2014 (O2 and E-Plus).

Two technology changes in the mobile industry, in its evolution from $2 \mathrm{G}$ to $4 \mathrm{G}$, started affecting the traditional view of regulatory and competition agencies. First, the mobile industry witnesses a process of disaggregation of the operational value chain, with the entry of Mobile Virtual Network Operators (MVNOs), with various degrees of reliance on the infrastructure of a Mobile Network Operator (MNO). A full MVNO is seen as an operator that relies on the access network of an MNO and owns assets to enable core network, value added services, back office, office definition and distribution channel. A Mobile Virtual Network Enabler (MVNE) is an operator in the middle of the value chain, relying on the access infrastructure of one or more host MNOs, and providing integrated services to multiple resellers. This disaggregation of the value chain determined both competitive and strategic behaviors (Lofti and Sarkar, 2017), compelling regulatory and competition agencies to monitor the behavior not only of competing facilities-based MNOs, but also the prices, wholesale and retails, and the level playing field within the value chain of a MNO.

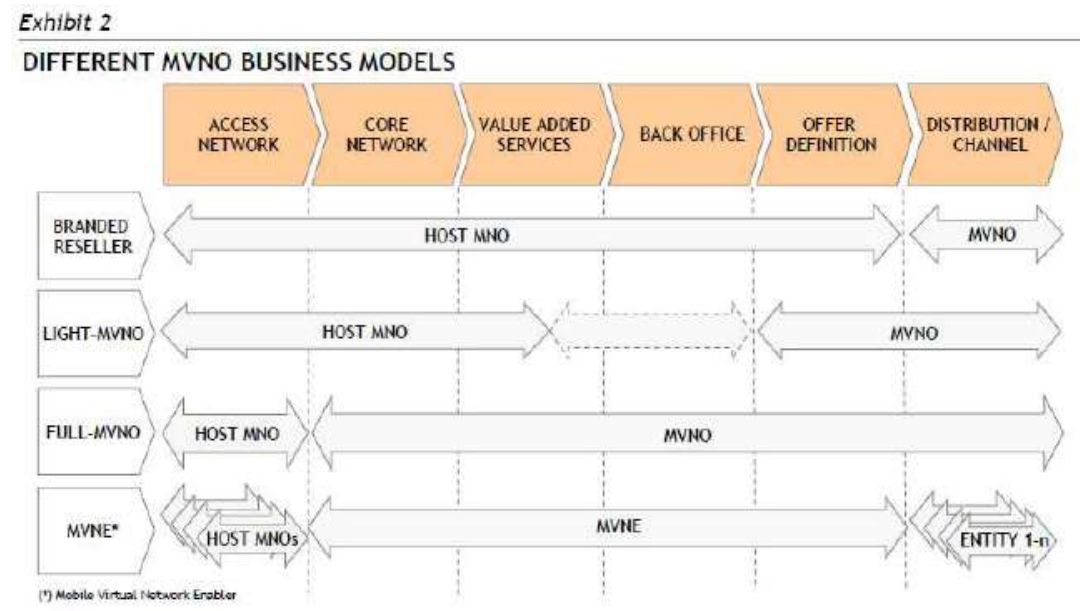

The second development is the emergence of data driven business models and applications. This shifted the regulatory and policy focus from the provision of access to essential infrastructure by competing facilitiesbased operators, to the relationship between an infrastructure-based operator and providers of data platforms and services. This prompted to call for an evolution of the current regulatory institutions and instruments, to address the reality of a multi-layered, all-IP, platform driven adjustment of the internet business model (Rossotto et. al, 2018). This is recognized in the study of regulation in multiplatform environment, for example, in Lehr et al. (2019): "it is necessary and desirable for that [new] regulator to have the authority and tools to regulate platform providers (or others) and to take corrective actions if market outcomes are not consistent with national communication policy goals. However, lest this turn into an unrestricted mandate for arbitrary regulation, we think it is important to be able to limit the newFCC's authority." (Lehr, Clark; Bauer, 2019). 
In a blog, former FCC Chairman Wheeler observes that "it is not the primary network that is transformative, but its secondary effects", adding that " $3 \mathrm{G}$ networks, for instance, were built on an economic model that did not anticipate how the iPhone would change the nature of those networks." (Wheeler, 2019). The emergence of the data economy brought a renewed focus on anti-trust. Among others, Rosston, 2010, indicates that antitrust analysis is well suited to determine whether a "wireless network neutrality rule is socially beneficial", concluding that a rule of reason analysis is needed to determine if certain vertical relationships behaviors, such as bandwidth restrictions, are justified from the economic efficiency standpoint. Rosston indicates that facilities-based competition in wireless softens the competition concerns. However, competition scrutiny is needed in the area of vertical relationships. The mobile industry started being affected by the same cost-benefit analysis considerations for vertical harm that were being applied by the regulatory authorities for the emerging "online video distribution" business, led by Amazon, Apple, Netflix. First delivered over fixed broadband, as the capacity of wireless communication started increasing, online video distribution become a concern of the mobile industry as well (Rosston, 2012). The vision of the seminal work of Ronald Coase, of a market driven electronic communications sector, with economic actors in an increasingly involved in a sophisticated set of transactional relationship was conspicuously confirmed by the evolution of the mobile industry. Coase's intuition that the "rearrangement of rights could be left to the market" found its realization in an evolving digitally enabled, data driven marketplace.

Behind the undoubtful novelty and transformational promise of $5 \mathrm{G}$ technology, there seem to be strong reasons to believe that the core features of $5 \mathrm{G}$ technology will place a further premium on market contestability, independent sector regulation and the intervention of anti-trust authorities in a data-driven business model. Contestability, regulation and antitrust intervention will be also the drivers of technology diffusion and adoption.

In a reflection on the role of anti-trust authorities in the digital space, Jamison observes that "Rather than attack firms for business practices that are at best difficult to understand because the antitrust view lacks context, antitrust regulators should look for and address unearned barriers or advantages that prohibit or distort the flow of economic resources that firms need to compete. There are several government actions that limit competitive processes and should be of interest to antitrust regulators. One is the grant of monopoly. The regulated monopolies were often inefficient, lacked innovation, and discriminated against rivals, and breaking up the monopoly was costly and time-consuming.” (Jamison, 2019).

Indeed, the first danger to a well-functioning $5 \mathrm{G}$ market would be a government decision to create a monopoly at any point across the value chain based on assumptions of cost synergies, or by invoking misplaced security concerns to restrict market forces. Neminem laedere should be the first policy principle.

5G introduces networks of dense cells supporting heterogeneous networks. This are known as Multi-Tier and Multi-Radio Access Technology Heterogenous Networks (HetNet). The "catallaxy" of a 5G network involves different players playing different roles and engaged in market exchanges. Multi-tier HetNet will involve the compatibility of the $5 \mathrm{G}$ network with $4 \mathrm{G} / \mathrm{LTE}$, and $3 \mathrm{G}$, with its associated value-chain disaggregation. The Multi-tier HetNet will overlay a cellular system with small cells of the same technology (micro-, pico- and femto- cells). Multi-RAT HetNet involves the integration of different Radio-Access Technologies, such as HSPA, WLAN and Wi-fi networks. The topic of competition versus cooperative dynamics among RATs operators has been identified as early as during the transition to $3 \mathrm{G}$ (Lehr, 2003). It is compounded in the move to 5G. Different network operators, using different technologies, and with different models, will all need to interact, following open standards that may require a certain degree of technical regulatory intervention and standardization 
Another 5G feature, network slicing, has the potential to place the MNO in a monopoly position with respect to the various providers of RATs within a single slice (Wheeler, 2019). For example, within the "massive IoT" network slice, the 5G MNO will coordinate multiple IoT providers, using different RATs. A bottleneck in the access price and conditions could discourage IoT investment, potentially exacerbating digital inclusion issues (Lee, 2019). Exclusive arrangements between the 5G MNO and an IoT operator may prevent the entry of other operators within that slice. In addition, K. Samdanis, X. Costa-Perez and V. Sciancalepore, 2016 envisaged the concept of 5G Network Slice Broker, enabling mobile virtual network operators, OTT, and verticals to use and lease "resources from infrastructure providers dynamically via signaling means.". In addition, Matinmikko et al. 2018, made a compelling case for "micro-licensing", with local access rights, expecially for the operations $6 \mathrm{GHz}$ bands, characterized by high propagation losses, and hence less inclined to create interference with other operators. The presence of multiple downstream players within each network slice, the prospect of 5G Network Slice Brokers, and the micro-licensees, all open the door for substantial innovation, private sector development and entrepreneurship, provided there are no excessive rents or capture by the $\mathrm{MNO}$, or government-imposed distortions. This evolution may introduce "the need for market analyses to confront situations in which network operators sell more and more of their services to a variety of heterogeneous content and application providers, and fewer and fewer services to end users." (Cave, 2018).

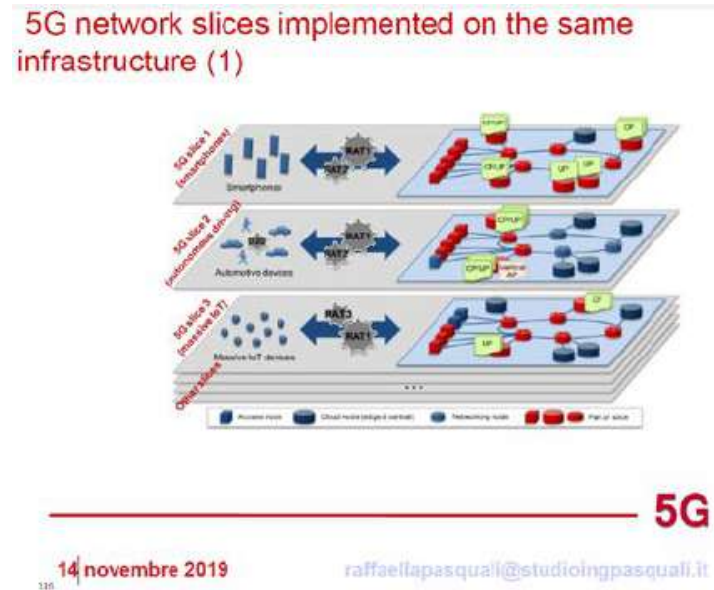

The massive improvement in speed and latency of $5 \mathrm{G}$, and the initial focus on video content, will also move the whole net neutrality debate to the mobile network, through a "review of current net neutrality regimes, to the extent that they outlaw the provision by ISPs of bespoke services to particular content and application providers" (Cave 2018). The development of millimeter wave RATs will require the deployment of antennas in many sites: "Coherent, distributed beam forming is effectively a geo-distributed sparse antenna array jointly forming, steering, and managing beams" (Harper and Deutsch, 2019). This will increase the scope for economies of scale and scope in network deployment, bringing pressures on MNOs not to replicate existing infrastructure. Hence, "a fully densified mobile network will approximate more closely than its predecessors to the cost conditions of a "natural monopoly'." (Cave, 2018). In this respect, Cave, among others, envisages a heavier regulation of fewer RANs. Additional issues will involve the location of the many antenna sites. It will be important that access to sites is not restricted or allowed at exorbitant prices. In addition, $5 \mathrm{G}$ will requires access to third party backhaul capacity at just and reasonable rates.

Software-defined networking (SDN) technology is expected to radically change network management through dynamic, programmatically efficient network configuration. The network architecture based on network functions virtualization (NFV) will virtualize entire classes of network node functions into 
building blocks that may connect, or chain together, to create communication services. The impact on network management is massive. Already, wireless cellular ISPs enable a distributed network of virtualized, cloud-based and programmable cellular base stations to communicate. This could prove a viable model, for example, to address rural communications challenges in emerging markets, as shown in Talal and Lakshminarayanan, 2017. In fixed broadband, adapting a broadband network development model to technology variations to address digital divide challenges has proved essential in the context WLAN solutions in the last mile, with a strong impact on local entrepreneurship and rural access (Puschita et al., 2014). 5G will imply the need to "reimagining of the core network to which the radio access network (RAN) delivers the signal. While earlier wireless generations had dedicated hardware at their core to route the signals and perform other network functions, $5 \mathrm{G}$ has moved those functions into software and put them in the cloud" (Wheeler, 2019)

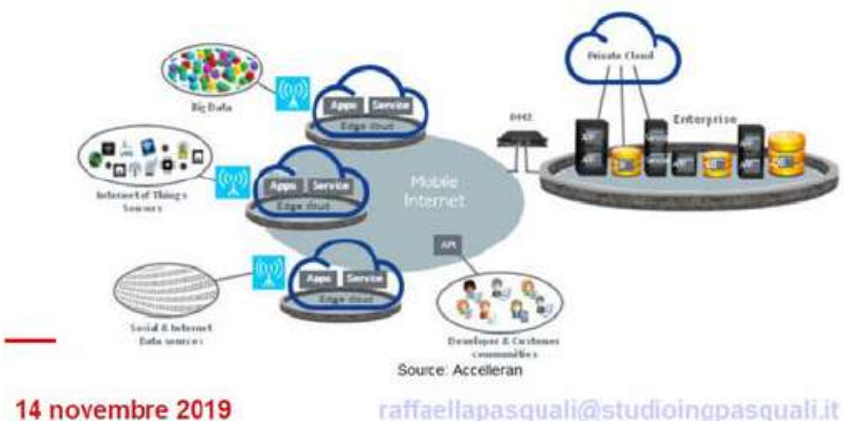

The changes to the framework of a vertical structure containing "more competitive and heterogeneous players in backhaul and core networks [...] may lead to commercial pressures on existing mobile operators to separate themselves as a more specialized RAN operator. Regulators might also be confronted with the prospect of mobile and fixed operators being relegated to a different role in parallel with their traditional one, as sellers of variegated network components to service providers which will own and control the relationship with the customer. This will require market analyses with a different focus and different levels of countervailing market power than are exhibited at present." (Cave, 2018)

\section{Analysis/Conclusion}

Accelerating the deployment of $5 \mathrm{G}$ in high income as well as emerging economies will require adherence, in primis, to the principles of market-based network, platforms and services development, coherent with the Coasian approach. Refraining from nationalization, monopolization, excessive government coordination and intervention is the first principle.

Second, the players in the emerging 5G catallaxy will find equilibria determined by prices, agreements, horizontal and vertical relationships, self and mandated standardization issues. Independent regulatory agencies should monitor the $5 \mathrm{G}$ emerging market to facilitate entry, contestability and the development of market-based solutions. This includes:

- $\quad$ releasing sufficient spectrum for commercial use, especially in the medium and high bands; 
- $\quad$ use licensing to proactively allow greater entry, including introducing new regulatory concepts such as V-ISPs and micro-licenses, facilitate the emergence of markets when disintermediation is possible, compounded by the network slicing;

- $\quad$ Promote fair and reasonably priced access to land and existing infrastructure facilities;

- $\quad$ Promote fair and reasonably priced access to backhaul;

- Monitor over possible abuse of dominant position, including in the vertical relationships, and within each network slice

Third, developing anti-trust capacities to go back to its original inspiring principle of making markets work, avoiding the emergence of monopolies, cartels and assessing the risk of abuse of dominant position. 

"Sur quoi la fondera-t-il l'économie du monde qu'il veut gouverner? Sera-ce sur le caprice de chaque particulier? Quelle confusion! Sera-ce sur la justice? Il l'ignore."

Pascal

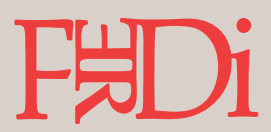

Created in 2003, the Fondation pour les études et recherches sur le développement international aims to promote a fuller understanding of international economic development and the factors that influence it.

\section{$\rightarrow$ Contact}

www.ferdi.fr

contact@ferdi.fr

+33 (o)4 73177530 